Las inserciones laborales de los/as jóvenes en la Argentina

Un análisis de los diferenciales por sexo durante la posconvertibilidad (2004-2017)

María Berenice Rubio, Emiliano Echevarría

Revista Argentina de Estudios de Juventud, (13), e026, 2019

ISSN 1852-4907 | https://doi.org/10.24215/18524907e026

https://perio.unlp.edu.ar/ojs/index.php/revistadejuventud

FPyCS | Universidad Nacional de La Plata

La Plata | Buenos Aires | Argentina

\title{
LAS INSERCIONES LABORALES DE LOS/AS JÓVENES EN LA ARGENTINA
}

\author{
UN ANÁLISIS DE LOS DIFERENCIALES POR SEXO \\ DURANTE LA POSCONVERTIBILIDAD (2004-2017)
}

\author{
The labor insertions of young people in Argentina: \\ An analysis of sex differentials during post-convertibility (2004-2017) \\ María Berenice Rubio \\ beer.rubio@gmail.com | https://orcid.org/0000-0002-9095-1138 \\ Emiliano Echevarría \\ emilianorechevarria@gmail.com |https://orcid.org/0000-0003-4253-7423
}

Instituto de Investigación Gino Germani

Facultad de Ciencias Sociales

Universidad de Buenos Aires |Argentina

Palabras clave

mercado de trabajo jóvenes

segmentación laboral diferenciales por sexo

\section{Resumen}

El artículo aborda la dinámica heterogénea del mercado laboral argentino y sus efectos sobre las inserciones laborales de la población joven, a partir de identificar las formas diferenciales que estas adquieren para los varones y para las mujeres de este grupo. El acento se coloca en el impacto que tienen el nivel educativo y el sector de inserción sobre la distribución de las posiciones laborales de calidad. El período de estudio abarca la posconvertibilidad (2004-2017) y se emplea una metodología cuantitativa a partir de los microdatos de la Encuesta Permanente de Hogares (EPH-INDEC).

\section{Abstract}

Keywords

labour market youth labour segmentation gender differentials
The article addresses the heterogeneous dynamics of the Argentine labor market and its effects on the labor insertions of the young population, identifying the differential forms they acquire for the men and women of this group. Emphasis is placed on the impact that the educational level and the insertion sector have on the distribution of quality work positions. The post-convertibility period (2004-2017) is approached using a quantitative methodology based on the microdata of the Permanent Household Survey (EPH-INDEC). 


\title{
LAS INSERCIONES LABORALES
}

\section{DE LOS JÓVENES EN LA ARGENTINA}

\author{
UN ANÁLISIS DE LOS DIFERENCIALES POR SEXO
}

DURANTE LA POSCONVERTIBILIDAD (2004-2017)

\section{Por María Berenice Rubio y Emiliano Echevarría}

\section{Introducción}

El encadenamiento de sucesivas crisis socioeconómicas y de procesos de recuperación, con sus respectivos planes de ajuste, ha impactado negativamente en las condiciones de vida de amplios sectores de la población latinoamericana. En el presente artículo se hace foco en el segmento poblacional de jóvenes, a partir de entender que sus condiciones de vulnerabilidad están fuertemente asociadas a la composición estructural del aparato productivo junto con el deterioro de la institucionalidad laboral y la erosión de las capacidades estatales de regulación.

La población joven, que se encuentra transitando el ingreso a la vida laboral, es uno de los grupos más afectados por el deterioro de las condiciones de empleo y, en este sentido, la literatura especializada ha podido confirmar que su inserción se produce, principalmente, en el sector menos dinámico de la estructura productiva (CEPAL-OIJ, 2004; Beccaria \& Groisman, 2015).

En el presente trabajo, partiremos de los estudios que se apoyan en explicaciones sobre la demanda de empleo, pero en articulación con el aporte que hace el análisis de las características propias de la oferta de fuerza de trabajo -como la edad, el sexo y el nivel educativo alcanzado- al estudio de la precariedad de sus puestos de trabajo. 
Distinguir en el análisis las diferencias por sexo aporta al estudio una mirada multidimensional sobre las desigualdades en la inserción laboral de la juventud en nuestro país. A partir de la incorporación de esta cuestión, se busca complejizar el enfoque de la demanda de empleo y sumar un condicionante propio de la oferta de la fuerza de trabajo considerado de importancia para pensar los perfiles de inserción demandados en el mercado de trabajo actual. En tanto, poner en discusión el rol del capital educativo permite centrar el análisis en aspectos estructurales del sistema económico argentino y en sus particulares efectos sobre las condiciones laborales de este grupo poblacional.

En este sentido, los interrogantes que guían el trabajo giran en torno a la dinámica heterogénea del mercado laboral argentino y a sus efectos -especialmente, en términos de calidad-sobre las inserciones laborales de la población joven bajo determinados contextos socioeconómicos. Principalmente, se buscan identificar las formas diferenciales que adquieren las inserciones laborales para los varones y para las mujeres del segmento poblacional comprendido entre los 18 y los 29 años de ocupados residentes en el total de aglomerados urbanos de la Argentina.

Así, se pone especial énfasis en evaluar, para ambos sexos, el impacto que tienen el nivel educativo y el sector de inserción en la calidad de sus posiciones laborales. El estudio aborda el período de la posconvertibilidad y los primeros años de la gestión de gobierno iniciada en 2015 y toma como años ventana de estudio los años 2004, 2007, 2011, 2014 y 2017. Para ello, se emplea una metodología cuantitativa que utiliza los microdatos de la Encuesta Permanente de Hogares (EPH) del Instituto Nacional de Estadísticas y Censos (INDEC).

\section{Coordenadas teórico metodológicas}

Los postulados teóricos estructuralistas latinoamericanos han cuestionado las estrategias de desarrollo que si bien lograron importantes avances en relación con el crecimiento económico dejaron afuera numerosos excedentes de población. En dicho sentido, son especiales antecedentes de este estudio aquellos enfoques que pensaron la reproducción del subdesarrollo en condiciones de dependencia económica y de heterogeneidad estructural (Prebisch, 1949; Pinto, 1970, 1976; 
Ocampo, 2001; Rodríguez, 2001). Este concepto remite a la coexistencia de un sector económico con una productividad media del trabajo relativamente próxima a la que permiten las técnicas disponibles a nivel del mercado mundial -y en el que se concentran las inversiones y el progreso técnico con un conjunto de actividades rezagadas-. Los patrones de empleo y de distribución que se originan a partir de esta estructura heterogénea tienden a ser profundamente regresivos.

Un aspecto fundamental en términos del impacto sobre el mercado de trabajo es la incapacidad del sector dinámico para absorber la totalidad de la fuerza de trabajo disponible en la sociedad, como resultado de lo cual una parte de ella se debe autoemplear en actividades de baja productividad (Prebisch, 1949; Pinto, 1976; Ocampo, 2001; Rodríguez, 2001). Esto último, sin dejar de tener en cuenta que las características de los ciclos macroeconómicos que atraviesa una economía también cumplen un papel importante en el comportamiento de la demanda agregada de empleo e influyen sobre las tasas generales de absorción de mano de obra.

La proyección de esta perspectiva sobre el campo de los estudios del trabajo se produjo a partir del Programa Regional de Empleo para América Latina y el Caribe (PREALC). De esta manera, el concepto de sector informal urbano se presenta como una clave analítica para entender el comportamiento de los mercados de trabajo de los centros urbanos y su vínculo con el desempleo (Tokman, 2004). Se recuperan, entonces, los lineamientos metodológicos propuestos por el Programa Cambio Estructural y Desigualdad Social que retoman el enfoque de PREALC-OIT (1978) donde, a partir del tamaño del establecimiento, del carácter público o privado de las unidades económicas y de la calificación profesional de los ocupados en el caso de los empleos no asalariados, se puede segmentar el tipo de inserción productiva según los diferenciales teóricos de productividad asociados a las unidades económicas. En este sentido, Agustín Salvia, Julieta Vera y Santiago Poy (2015) distinguen tres tipos de ocupaciones en el mercado de trabajo: ocupaciones en el sector público, ocupaciones en el sector privado, moderno o formal, y ocupaciones en el sector microempresario informal. ${ }^{1}$

Asimismo, desde el enfoque institucionalista norteamericano, la demanda laboral queda estratificada en tres grandes segmentos de empleo: segmento primario o empleos regulados, segmento secundario o empleos extralegales y segmento terciario o empleos de indigencia, como empleos no regulados. ${ }^{2}$ De acuerdo a esta 
corriente, no existe un único mercado de trabajo sino diferentes segmentos bajo marcos institucionales disímiles, que representan desiguales modalidades de inserción, de relaciones laborales y de calidad de los puestos de trabajo (Piore, 1975).

En este contexto, cabe preguntarse por el lugar que ocupa la población joven en el marco de sociedades heterogéneas y segmentadas. Particularmente, en la Argentina la problemática de la exclusión juvenil ha cobrado marcada relevancia en la agenda pública debido a la persistencia de altas tasas de desocupación y de inestabilidad laboral que afectan a este grupo etario. En este sentido, existe consenso acerca de que los jóvenes constituyen uno de los grupos más perjudicados por la crisis del mercado laboral argentino y de que, además, el deterioro que atraviesan sus inserciones socio ocupacionales son difícilmente reversibles a lo largo de sus trayectorias laborales (Jacinto, 2004; CEPAL-OlJ, 2004; Miranda, Otero \& Zelarayan, 2005; Pérez, 2008; CEPAL, 2014, 2015).

Se discutirá con los argumentos que priorizan el capital educativo (Schultz, 1961; Becker, 1962; Terrones \& Calderón, 1993; Perry y otros, 2007; Gallart, 2008), las competencias escolares y profesionales necesarias para el ingreso al mercado laboral por sobre los mecanismos de diferenciación socio económica, así como con los que sugieren medidas de promoción de políticas de empleo juveniles que no han llegado a mejorar la inserción de la población joven que más requiere de dichas compensaciones (Weller, 2003; CEPAL-OIJ, 2004; Banco Mundial, 2005).

Investigaciones precedentes han confirmado que las mujeres son quienes realizan mayoritaria y simultáneamente actividades productivas y reproductivas, lo cual produce cambios en la vida familiar y refuerza patrones de subordinación y de desigualdad entre hombres y mujeres. En particular, en tanto los contenidos, los modelos y las prácticas sociales sobre el trabajo que en la transición de la juventud a la adultez se reproducen de forma desigual para hombres y mujeres, la referencia a la brecha en la división sexual del trabajo resulta ineludible (Esquivel, 2007; Salvia \& Tuñón, 2007; Rojo Brizuela \& Tumini, 2009; Halperín Weinsburd y otros, 2009, 2011; Mileenar \& Jacinto, 2015; OIT, 2016a, 2016b; Pérez \& Busso, 2018). Las mujeres siguen en desventaja respecto a todos los indicadores laborales y continúan enfrentándose a discriminaciones, explícitas o encubiertas, tanto en sus procesos 
de inserción como en la posibilidad de construir carreras profesionales. La presencia femenina suele ser mayor también en el trabajo no remunerado que se realiza al interior de los hogares (Espino, 2011; Novick, Rojo \& Castillo, 2008).

Pese a contar con las mismas credenciales educativas, las mujeres son discriminadas en el mercado de trabajo, lo que se manifiesta en las desiguales oportunidades, salarios y estabilidad de los empleos de varones y de mujeres jóvenes. En este sentido, las mujeres están sobrerrepresentadas en algunas ocupaciones (servicio doméstico remunerado en casas particulares y en actividades relacionadas con la educación y otros cuidados), sin poder disminuir la segregación horizontal. De la misma manera, el efecto llamado «techo de cristal» deja ver la persistencia de la segregación vertical que las deja muy poco representadas en empleos de posiciones jerárquicas.

Al segmentar la población según sexo para incorporar al análisis condicionantes vinculados al perfil de la oferta, si bien la importancia que se observa en el peso de los factores estructurales de la demanda de empleo continúa siendo importante, se contemplan algunas particularidades que presenta la oferta de trabajo joven en términos de arreglos, que son bien diferentes por el sexo y por el rol que ocupan en los hogares que conforman, las cuales adquieren gran relevancia en el análisis.

Algunas investigaciones europeas (Grimshaw y otros, 2017) vienen impulsando la necesidad de una nueva y multidimensional forma de entender las inequidades en el mundo del trabajo. Este nuevo enfoque lleva a reflexionar en torno a las acciones políticas y económicas que están continuamente modelando las desigualdades laborales, en un contexto de transformación de los patrones internacionales de organización de la producción, de las relaciones laborales, pero también de las relaciones de género, los cambios demográficos -como el envejecimiento de las poblaciones- y los flujos migratorios.

Tales líneas argumentativas destacan que si bien los comportamientos de los mercados y el cambio tecnológico son de importancia, al igual que las tendencias a largo plazo en los ciclos de crecimiento económico, esto no alcanza para explicar por completo las divergentes caras de la desigualdad. Lo distintivo, entonces, es que propone pensar la segmentación desde la configuración institucional en la desigualdad del mercado de trabajo, incorporando, especialmente, una mirada comparativa de género sobre los efectos institucionales en la desigualdad. 
La interseccionalidad es un desarrollo ineludible del feminismo no-hegemónico que desde los años setenta ha cuestionado la perspectiva blanca, heterosexual y de clase media. Su novedad consistió en enfatizar sobre la constitución mutua y simultánea de discriminaciones y de privilegios (La Barbera, 2016). Es reconocido por estudiar las desigualdades que son interdependientes, en sus dimensiones enlazadas históricamente, a nivel micro y macro social, evitando reducciones unidimensionales. Es decir, permite examinar la forma en la que las diferentes distinciones sociales se interrelacionan tanto en términos de la producción de las relaciones sociales como en la vida de las personas (Else-Quest \& Hyde, 2016; Krause \& Ballesteros, 2018). Abarca la interconexión entre clase, género y otras divisiones sociales considerando los efectos de las estructuras de desigualdad a nivel micro, al mismo tiempo que cuestiona las formas en que múltiples instituciones y procesos se involucran en las construcciones sociales de poder y de privilegio (Bilge, 2010).

Es importante retomar esta teoría, ya que es una forma de caracterizar al sistema de estratificación social en su conjunto, mientras que hay otro tipo de estudios que asocian desigualdades con ciertos sistemas o instituciones, como puede ser las clases sociales con la economía o el género con la familia, y, de esa forma, más que aplicar un análisis interseccional, explican las contradicciones de los grupos no dominantes al interior de un sistema o institución (Choo \& Ferree, 2010). ¿Es, entonces, el género una relación social que viene a «empeorar» las desigualdades de clase o, en este caso, la condición de vulnerabilidad de la juventud, u otras? ¿La discriminación múltiple puede reducirse a un problema de sumatoria que explica las diversas experiencias de las mujeres? ¿O es que el género, la clase social, la edad, la etnia, etc., se coconstituyen al interactuar, estructurando posiciones sociales complejas?

En este sentido, analizar la posición de vulnerabilidad de la población joven en la estructura social, y la diversidad de experiencias de discriminación en el mercado laboral argentino que atraviesa este grupo, requiere de una mirada integradora capaz de dar cuenta de la complejidad, que enfatice en la relacionalidad con el género, por ejemplo, en donde se constituyen y se ejercen esas formas de discriminación. 
Respecto al contexto socioeconómico del periodo analizado, se toma como punto de partida la salida del modelo de la convertibilidad -pos crisis 2001 y 2002-, que deja un saldo de importantes alteraciones en el funcionamiento de los indicadores básicos del mercado de trabajo e instala debates en torno a lo que significaron las reformas estructurales de los noventa en la Argentina, y sobre algunas continuidades de la estructura ocupacional. Se analizan en el estudio el año 2004, como reflejo del principio de recuperación pos crisis; el año 2007, como momento álgido de dicho subperíodo previo a la crisis internacional 2008-2009; los años 2011 y 2014, como años de desaceleración, amesetamiento y crisis hacia el final de los gobiernos de signo heterodoxo (Feliz, López \& Álvares Hayes, 2009; Salvia \& Vera, 2011; Muñíz Terra, Pla y López Castro, 2016); y el año 2017, como ventana de estudio a la nueva coalición de gobierno de Cambiemos, con la incorporación de cambios pero también con ciertas continuidades respecto a la última fase del gran periodo heterodoxo (Cantamutto \& Schorr, 2016; CIFRAFLACSO, 2016; Arelovich y otros, 2017; Vommaro \& Gené, 2017; Freytes \& Niedzwiecki, 2018; Flores y otros, 2018).

Los/as jóvenes en el mercado de trabajo argentino

El momento transicional de la fuerza de trabajo joven en el ciclo de vida, y especialmente en el mundo laboral, explica las diferencias con el grupo de adultos/as. Numerosos antecedentes teóricos han confirmado que los/as jóvenes continúan accediendo a empleos de menor calidad que los/as adultos/as y que tienen mayores dificultades para mantenerlos (Busso \& Pérez, 2010; Pérez, Deleo \& Fernández Massi 2013; Fernández Massi, 2014; Rubio \& Salvia, 2018; Rubio \& Fachal, 2018).

Por esto, comenzaremos por comparar una serie de indicadores generales del mercado laboral al interior de la población joven y analizaremos, particularmente, los diferenciales de sexo [Cuadro 1]. Dado que el sexo, de por sí, es una dimensión central en la agenda pública para pensar el mercado de trabajo argentino, interesa destacar lo específico respecto de la desigual composición de la estructura de empleo para este sector (De Oliveira \& Ariza, 1997; Cerrutti, 2000; Salvia \& Tuñón, 2007; CEPAL, 2007; PNUD, 2014). 


\begin{tabular}{|l|c|c|c|c|c|c|c|c|c|c|}
\hline \multicolumn{1}{|c|}{ Año } & \multicolumn{2}{|c|}{2004} & \multicolumn{2}{c|}{2007} & \multicolumn{2}{c|}{2011} & \multicolumn{2}{c|}{2014} & \multicolumn{2}{c|}{2017} \\
\hline \multicolumn{1}{|c}{ Sexo } & Varón & Mujer & Varón & Mujer & Varón & Mujer & Varón & Mujer & Varón & Mujer \\
\hline Tasa de actividad $^{3}$ & $79,0 \%$ & $57,8 \%$ & $75,4 \%$ & $56,1 \%$ & $74,5 \%$ & $51,2 \%$ & $72,5 \%$ & $50,9 \%$ & $72,0 \%$ & $51,8 \%$ \\
\hline Tasa de empleo $^{4}$ & $65,6 \%$ & $44,9 \%$ & $68,3 \%$ & $47,2 \%$ & $66,0 \%$ & $42,9 \%$ & $64,1 \%$ & $42,8 \%$ & $64,0 \%$ & $42,1 \%$ \\
\hline Tasa de desocupación $^{5}$ & $16,9 \%$ & $22,4 \%$ & $9,4 \%$ & $15,9 \%$ & $11,5 \%$ & $16,3 \%$ & $11,6 \%$ & $15,9 \%$ & $11,2 \%$ & $18,7 \%$ \\
\hline Tasa de subocupación $^{6}$ & $12,8 \%$ & $15,1 \%$ & $6,7 \%$ & $12,2 \%$ & $7,8 \%$ & $11,0 \%$ & $9,6 \%$ & $13,3 \%$ & $12,1 \%$ & $14,2 \%$ \\
\hline Tasa de asalarización $^{7}$ & $84,6 \%$ & $80,7 \%$ & $86,6 \%$ & $81,8 \%$ & $87,6 \%$ & $80,4 \%$ & $86,2 \%$ & $77,7 \%$ & $84,5 \%$ & $76,8 \%$ \\
\hline Tasa de inactividad $^{8}$ & $21,0 \%$ & $42,2 \%$ & $24,6 \%$ & $43,9 \%$ & $25,5 \%$ & $48,8 \%$ & $27,5 \%$ & $49,1 \%$ & $28,0 \%$ & $48,2 \%$ \\
\hline Inactivos que estudian $^{9}$ & $74,6 \%$ & $47,8 \%$ & $70,3 \%$ & $45,8 \%$ & $73,3 \%$ & $48,2 \%$ & $68,6 \%$ & $46,9 \%$ & $71,5 \%$ & $51,8 \%$ \\
\hline
\end{tabular}

Cuadro 1 | Tasas de actividad, de desocupación, de subempleo horario y de inactividad sobre la población joven (18 a 29 años) económicamente activa y ocupada, según sexo. Total de aglomerados urbanos 2004-2017.

Fuente: elaboración propia sobre la base de la información procesada por el Programa Cambio Estructural y Desigualdad Social del Instituto Gino Germani (FCS-UBA), a partir de la EPH, INDEC, cuartos trimestres, 2004, 2007, 2011, 2014 y 2017

Las mediciones realizadas por el INDEC en los años analizados indican que la tasa de actividad de varones jóvenes es siempre mayor que la de mujeres jóvenes por, al menos, 19 puntos porcentuales aunque la tendencia descendiente es similar para ambos sexos: la tasa disminuye de $79 \%$ a $72 \%$ para los varones y de $58 \%$ a $52 \%$ para las mujeres, punta a punta del período. Para los varones, la caída más fuerte de la tasa se produjo en el período 2004-2007; para las mujeres, una caída similar se produjo en el período siguiente, 2007-2011, lo que permite pensar que el efecto coyuntura no impacta en la actividad de ambos sexos de igual manera.

Lo anterior indicaría que la tasa de inactividad fue aumentando con los años -ya que es la tasa complementaria de la de actividad- y que, por ende, fue aumentando mayoritariamente para las mujeres. En efecto, es mucho mayor para las mujeres que para los varones, observándose la menor diferencia (19 puntos) en 2007. La evolución es similar para ambos sexos ya que, punta a punta del período, asciende de $21 \%$ a $28 \%$ para los varones y de $42 \%$ a $48 \%$ para las mujeres. La escalada mayor se produce entre 2004 y 2007 para los varones, y entre 2007 y 2011 para las mujeres. 
En muchos casos, las mujeres jóvenes no solo se encargan de las tareas de cuidado al interior del hogar sino que, además, asisten a algún establecimiento educativo mientras las llevan a cabo -sin dejar de reconocer, como señalan estudios sociodemográficos recientes, que pertenecen a generaciones que postergan cada vez más las primeras uniones y la conformación de una familia propia (Cerrutti \& Binstock, 2009)-. Como señalan Pablo Pérez y Mariana Busso (2018), el concepto de división sexual del trabajo es potente en tanto la brecha refiere a que los jóvenes son preparados para asumir las responsabilidades de un trabajo productivo mientras que las jóvenes cargan con el mandato de contribuir a la reproducción en el ámbito doméstico.

Definitivamente, esto afecta las posibilidades laborales de las mujeres, quienes ocupan desde jóvenes los empleos más precarios y peor remunerados. El peso del trabajo doméstico no remunerado, traducido en mayor cantidad de horas diarias dedicadas a estas tareas, dificulta sus posibilidades de estudiar y/o de trabajar. En el caso de las mujeres, la juventud opera como un aspecto de la segregación que es en sí misma un modo de exclusión y de desigualdad social (De Oliveira, 2006; Rubio \& Salvia, 2018).

En este sentido es que presentamos entre los inactivos el porcentaje de los que asisten a un establecimiento educativo, ya que entendemos que el hecho de estar estudiando es el principal motivo de inactividad en la población joven, lo que varía en el interior del período entre un mínimo de 54\%, registrado en 2007, y un máximo de 59\%, en 2017 [Gráfico 1]. Efectivamente, podríamos inferir que más de la mitad de los jóvenes inactivos probablemente lo sean por encontrarse estudiando.

En tanto, no es un porcentaje despreciable que dentro de los jóvenes inactivos $40 \%$ no asista a un establecimiento educativo, es decir, que su motivo de inactividad no esté asociado a encontrarse estudiando. Además, al considerar los sexos por separado encontramos una importante diferencia: entre las mujeres inactivas quienes no estudian representan, aproximadamente, la mitad del total; entre los varones, quienes no asisten a un establecimiento educativo representan valores cercanos a la cuarta parte. 


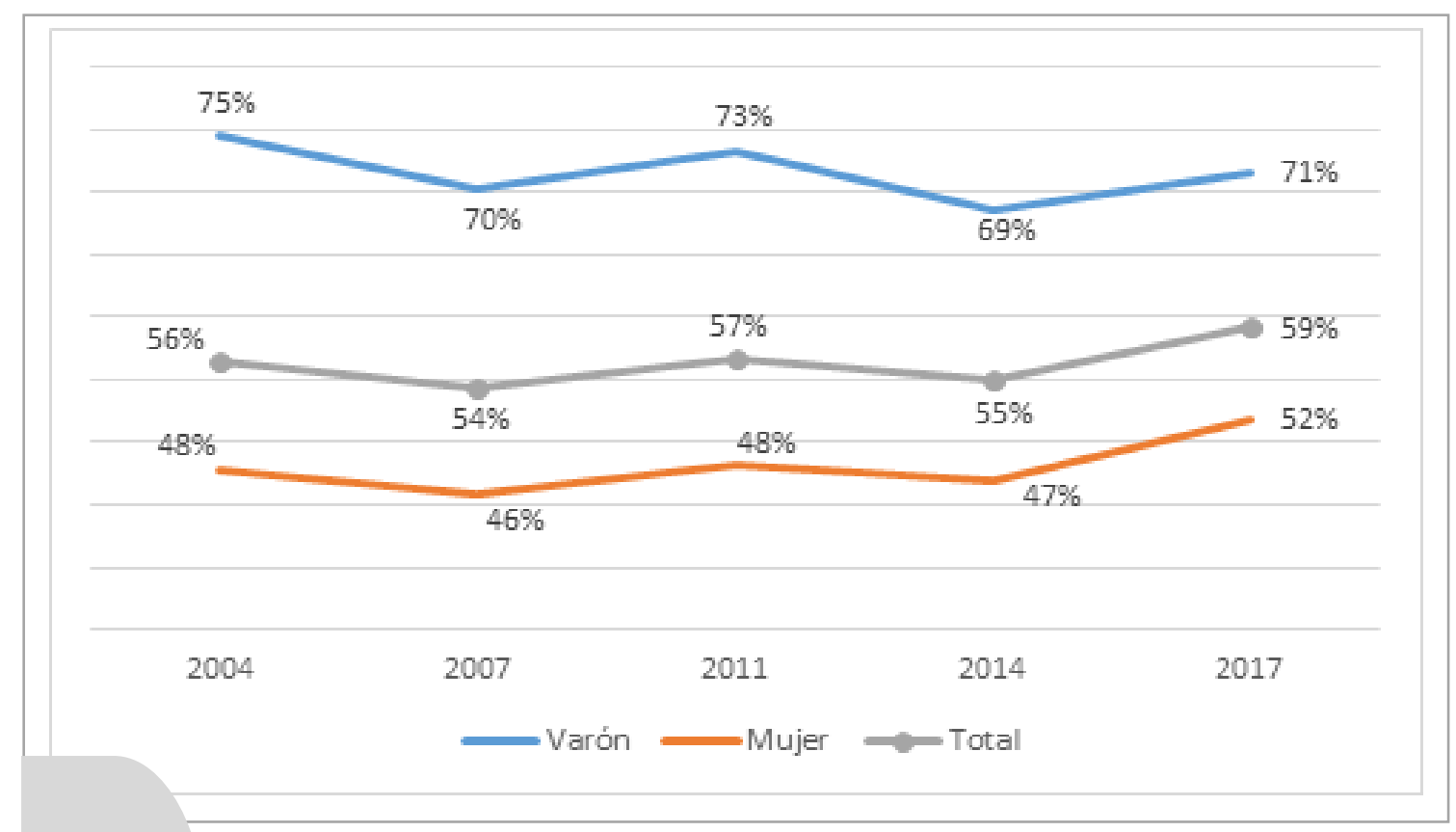

Gráfico 1 | Evolución del porcentaje de inactivos, de 18 a 29 años, que asisten a un establecimiento educativo. Total de aglomerados urbanos 2004-2017.

Fuente: elaboración propia sobre la base de la información procesada por el Programa Cambio Estructural y Desigualdad Social del Instituto Gino Germani (FCS-UBA), a partir de la EPH, INDEC, cuartos trimestres, 2004, 2007, 2011, 2014 y 2017

No es objeto de este estudio profundizar en los motivos de inactividad de la población joven, no obstante, resulta de interés destacar estas tasas y diferenciarlas por sexo, ya que dan cuenta de la participación en el mercado laboral. Numerosas investigaciones han analizado los diferenciales de participación en la esfera del trabajo productivo y en la del reproductivo; la división entre «casa» y trabajo y cómo los patrones socioculturales determinan los espacios y los tiempos sobre el rol de cada integrante del hogar, especialmente según sexo. Pareciera que los/as jóvenes, aun siendo mayoritariamente hijos e hijas y, por lo general, trabajadores/as secundarios/as en el hogar, no escapan de estos análisis, sobre todo, cuando se los diferencia por sexo.

Respecto a la tasa de desocupación, la mayor caída se produce en el período 2004-2007, en consonancia con la salida de la crisis, puesto que desciende de $19 \%$, valor máximo registrado en el período, a 12\%, el valor mínimo. Más allá de los vaivenes de la coyuntura, se observa una significativa diferencia entre la tasa de desocupación de varones y de mujeres jóvenes a lo largo del período. En el caso de los varones, el mayor ascenso de la tasa de desocupación se observa en el 
período 2007-2011, al cabo del cual alcanza 12\% y se mantiene muy similar por el resto del período. En el caso de las mujeres, la evolución de esta tasa es diferente y presenta mayor coincidencia con los vaivenes de la coyuntura: luego del descenso entre 2004 y 2007, se mantiene estable en 16\% y vuelve a escalar entre 2014 y 2017 a $19 \%$.

La tasa de subempleo es también mayor para las mujeres durante todo el período pero la brecha no se mantiene constante: se produce un descenso entre 2004 y 2011, para luego volver a ascender entre 2011 y 2017, hasta alcanzar 14\%. En el caso de los varones, se aprecia una fuerte caída de 6 puntos entre 2004 y 2007, seguida por un ascenso continuado en el resto del período hasta alcanzar $12 \%$. En este sentido, puede observarse el efecto coyuntural para ambos pero especialmente para los varones. De todos modos, independientemente de la coyuntura, las mujeres se encuentran en situación de subempleo de forma constante, asociado a lo ya destacado anteriormente: continúan siendo las principales proveedoras de cuidado dentro de sus hogares, encontrándose sobrerrepresentadas como trabajadoras familiares auxiliares y aceptando empleos más flexibles, de menos horas semanales y, por lo general, precarios (PNUD, 2014).

También se observa que los varones mantienen una tasa de asalarización mayor a la de las mujeres a lo largo de todo el período. Mientras para los varones comienza en 85\%, asciende 2 p.p. para 2011 y vuelve al valor inicial en 2017; para las mujeres, el valor de esta tasa comienza en $81 \%$, aumenta a $82 \%$ en la siguiente medición y desciende hasta llegar a 77\% en 2017. De este modo, la diferencia porcentual entre los sexos se acentúa con el correr de los años ya que se inicia en $4 \%$ y aumenta hasta duplicar ese valor.

Esta situación de desventaja en la que se posicionan las mujeres en el mercado de trabajo, la cual ha sido relevada por numerosos análisis, se vincula con prácticas de contratación discriminatorias por parte de las empresas pero, también, con el hecho de que las mujeres trabajan menor cantidad de horas que sus pares hombres -involuntariamente- y generan menores ingresos laborales mensuales -incluso, habiendo alcanzado mayores niveles educativos- (Esquivel, 2007; Novick, Rojo \& Castillo, 2008; CEPAL, 2010; MTEySS \& INDEC, 2014; OIT, 2016a). 


\section{Composición del mercado de trabajo \\ según nivel educativo, sector de inserción y segmento de empleo}

Bajo el supuesto de que en el grupo de trabajadores/as jóvenes se profundizan problemáticas comunes al mercado de trabajo en general, pero considerando que se trata de un grupo particularmente vulnerable, sobre todo, en términos de la calidad de los puestos a los que acceden, se analiza, a continuación, la composición del mercado de trabajo argentino para este grupo, según nivel educativo, sector de inserción y segmento de empleo, diferenciado por sexo, nueva variable que resulta de interés dados los signos de relevancia analítica mostrados en el apartado anterior.

\section{Según nivel educativo}

A lo largo del período, los/as ocupados/as jóvenes se componen aproximadamente de una tercera parte de cada uno de los niveles educativos, con diferencias máximas de 13\% entre los niveles. Punta a punta del período, el nivel inferior, «hasta secundario incompleto ( $\mathrm{HSI}$ )", disminuye en forma continua de 39\% a 32\%; el nivel intermedio, "secundario completo (SC)», aumenta de forma sostenida de $26 \%$ a $32 \%$; el nivel superior, "terciario y universitario incompleto o completo (TUIC)", representa entre 35\% y $37 \%$ pero sin describir una tendencia continua [Gráfico 2].

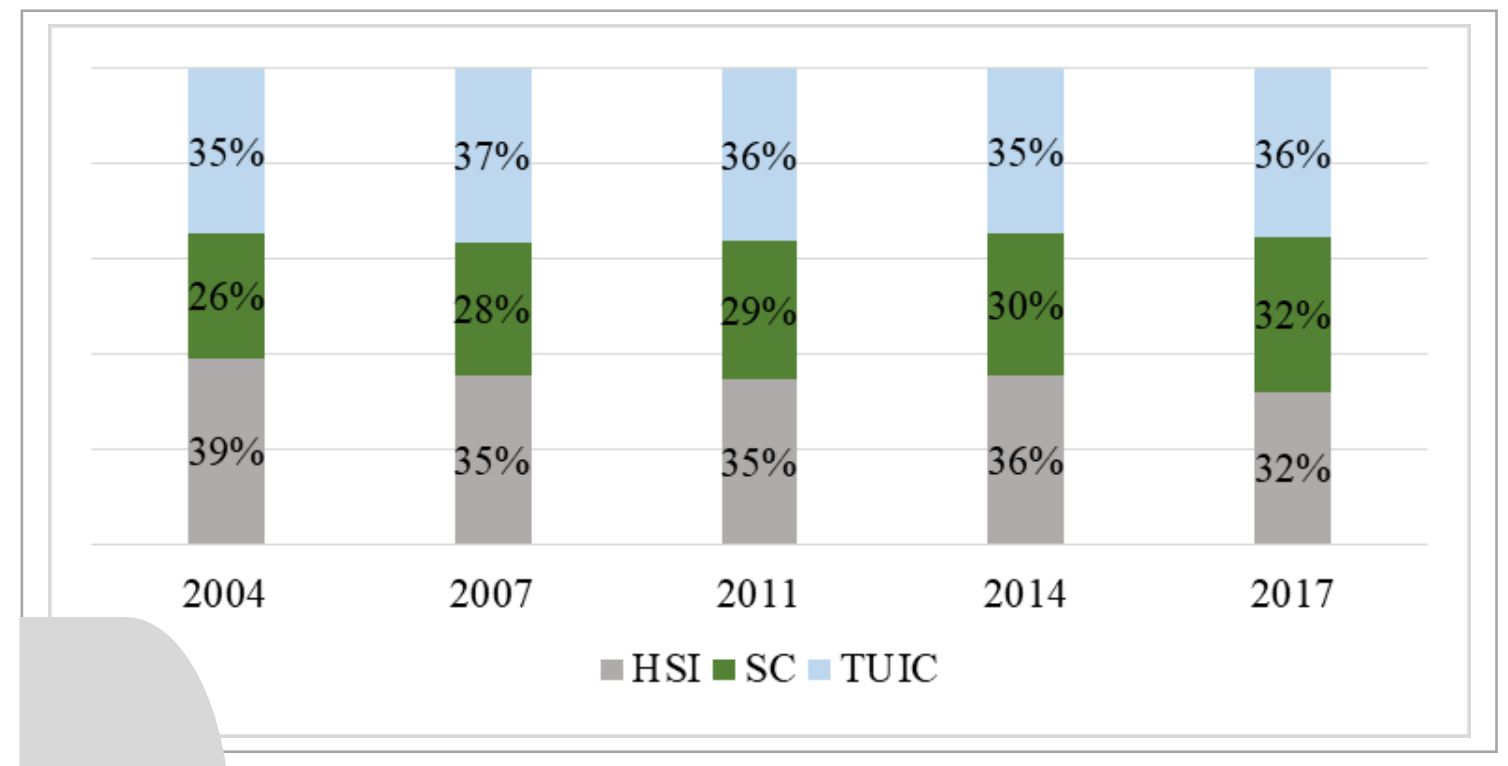

Gráfico 2 | Composición de la fuerza de trabajo ocupada joven,

de 18 a 29 años, por nivel educativo. Total de aglomerados urbanos 2004-2017.

Fuente: elaboración propia sobre la base de la información procesada por el Programa Cambio Estructural y Desigualdad Social del Instituto Gino Germani (FCS-UBA), a partir de la EPH, INDEC, cuartos trimestres, 2004, 2007, 2011, 2014 y 2017 
En relación con este aspecto, es importante señalar que a partir de la Ley Nacional de Educación 26.206/06 se implementó en la Argentina una política de extensión de los años de escolarización obligatoria de la escuela media (UNICEF, 2008) que permite identificar un incremento general en las posibilidades de contar con mayores titulaciones y pone de manifiesto el aumento de accesibilidad a la educación de la población en general, con la subsiguiente incorporación al mercado de trabajo de trabajadores/as en promedio más educados/as (Gasparini, Galiani, Cruces \& Acosta, 2011; Salvia \& Vera, 2011; Beccaria, Maurizio \& Vázquez, 2015).

Se observa, a su vez, una gran diferencia educativa entre los varones y las mujeres ocupados jóvenes [Gráficos 3 y 4]. En nuestra región, las mujeres -especialmente, las ocupadas- presentan un elevado nivel educativo, condición que, en su mayoría, no se corresponde con la calificación de las tareas que desarrollan (CEPAL, 2007; PNUD, 2011). El porcentaje de mujeres ocupadas con educación superior duplica al de sus pares hombres, llegando a un tercio del total de las mujeres ocupadas. En tanto, el porcentaje de trabajadores con niveles educativos inferiores a secundario completo es marcadamente superior entre los hombres (PNUD, 2014).

En ambos niveles, las diferencias entre los sexos oscilan entre $16 \%$ y $23 \%$. Asimismo, con el transcurso de los años se aprecia una disminución del nivel inferior en ambos sexos junto con un aumento del nivel intermedio. En cuanto a los/as más educados, mientras que para las mujeres se describe una tendencia de aumento sostenido, de $45 \%$ a $49 \%$, para los varones se observa una oscilación entre $26 \%$ y $30 \%$.

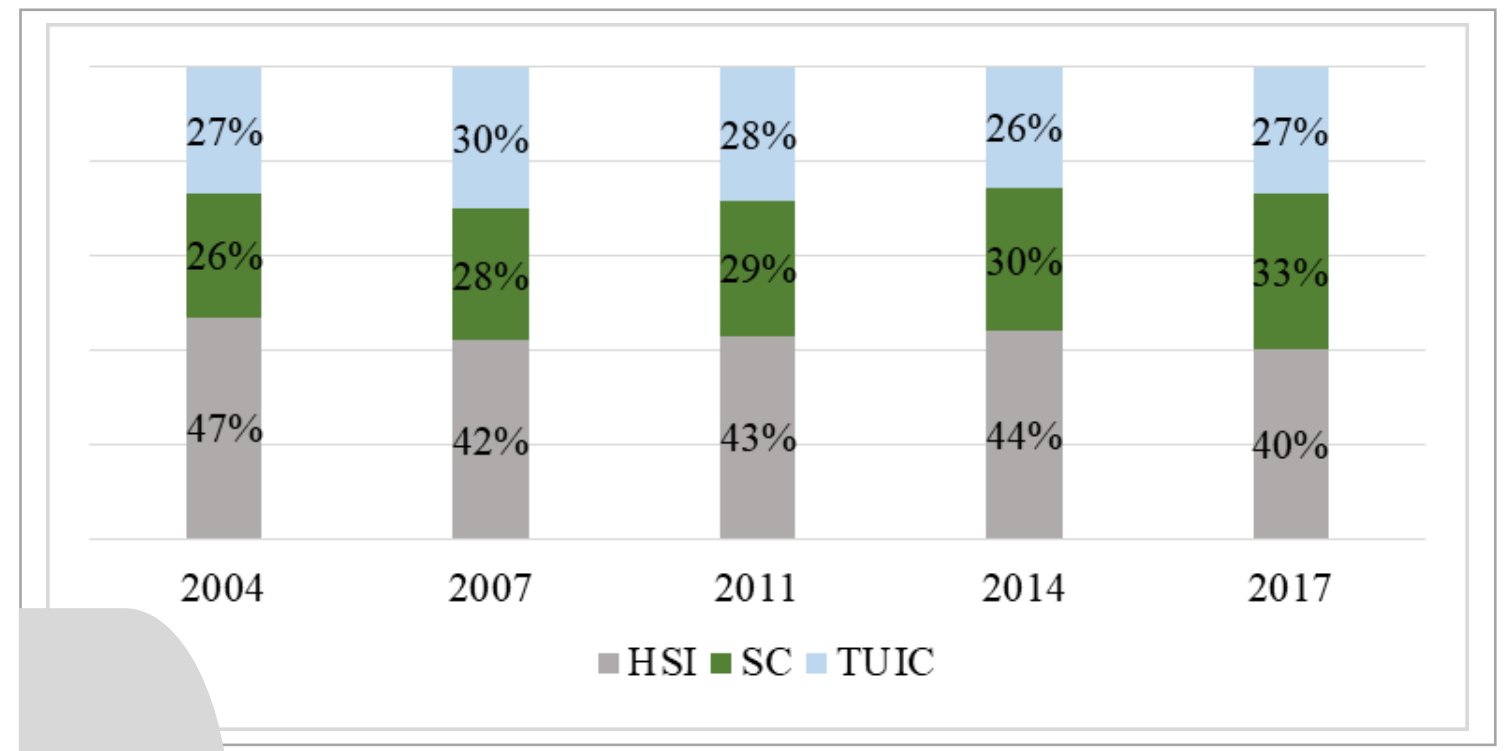

Gráfico 3 | Composición de la fuerza de trabajo masculina ocupada joven, de 18 a 29 años, por nivel educativo. Total de aglomerados urbanos 2004-2017. 


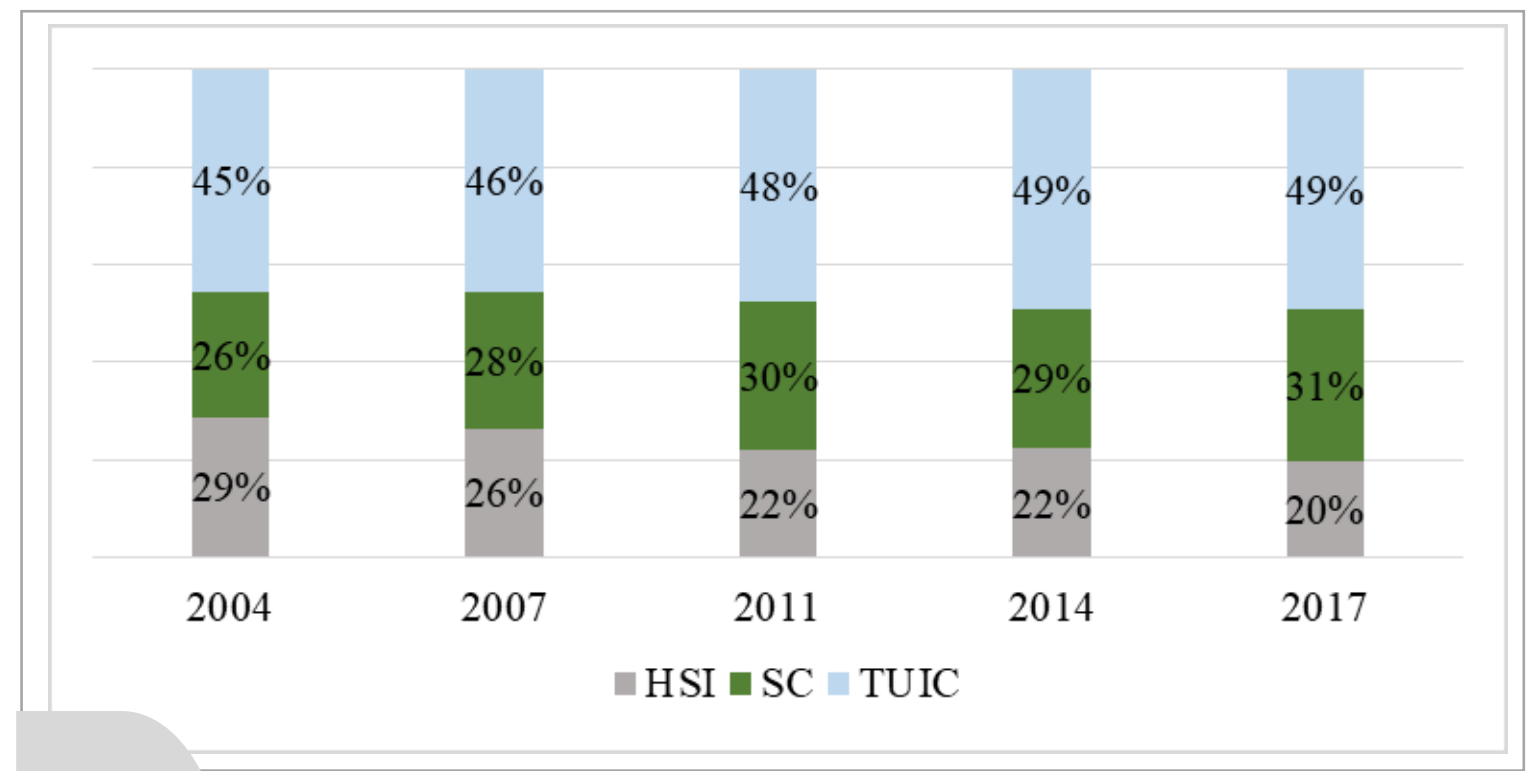

Gráfico 4 | Composición de la fuerza de trabajo femenina ocupada joven, de 18 a 29 años, por nivel educativo. Total de aglomerados urbanos 2004-2017.

Fuente: elaboración propia sobre la base de la información procesada por el Programa Cambio Estructural y Desigualdad Social del Instituto Gino Germani (FCS-UBA), a partir de la EPH, INDEC, cuartos trimestres, 2004, 2007, 2011, 2014 y 2017

La mayor educación formal de las mujeres, sin embargo, no parece facilitarles el acceso a puestos jerárquicos, ya que los hombres acceden a dichos puestos en mayor medida aún con las mismas credenciales. La segregación vertical pone de manifiesto que, a pesar de presentar niveles de formación iguales o superiores, los cargos a los que se accede no son los mismos entre los varones y las mujeres.

\section{Según sector de inserción}

En cuanto a la composición general de este grupo, a lo largo del período se insertan en similares proporciones tanto en el sector formal como en el informal, con porcentajes que oscilan entre $41 \%$ y $48 \%$, mientras que el sector público recluta, aproximadamente, la décima parte de los/as ocupados/as. El porcentaje de ocupados/as en este sector aumenta y se mantiene en $11 \%$ hasta el final del periodo, en coincidencia con el aumento de la participación en este sector [Gráfico 5].

La evolución de cada uno de los sectores a lo largo del período reproduce, para ambos sexos, la tendencia descripta para el total de los jóvenes ocupados, aunque no siempre con la misma intensidad. En todos los años, el porcentaje de varones ocupados en el sector formal es mayor que el de las mujeres, mientras que los porcentajes de varones ocupados en el sector informal y en el sector público son 
menores a los de las mujeres [Gráficos 6 y 7]. Esto se asocia a la segregación horizontal, es decir, a la exclusión dentro de las diferentes ramas laborales, donde se identifican trabajos que son mayormente realizados por varones y actividades que quedan en manos, casi exclusivamente, de mujeres.

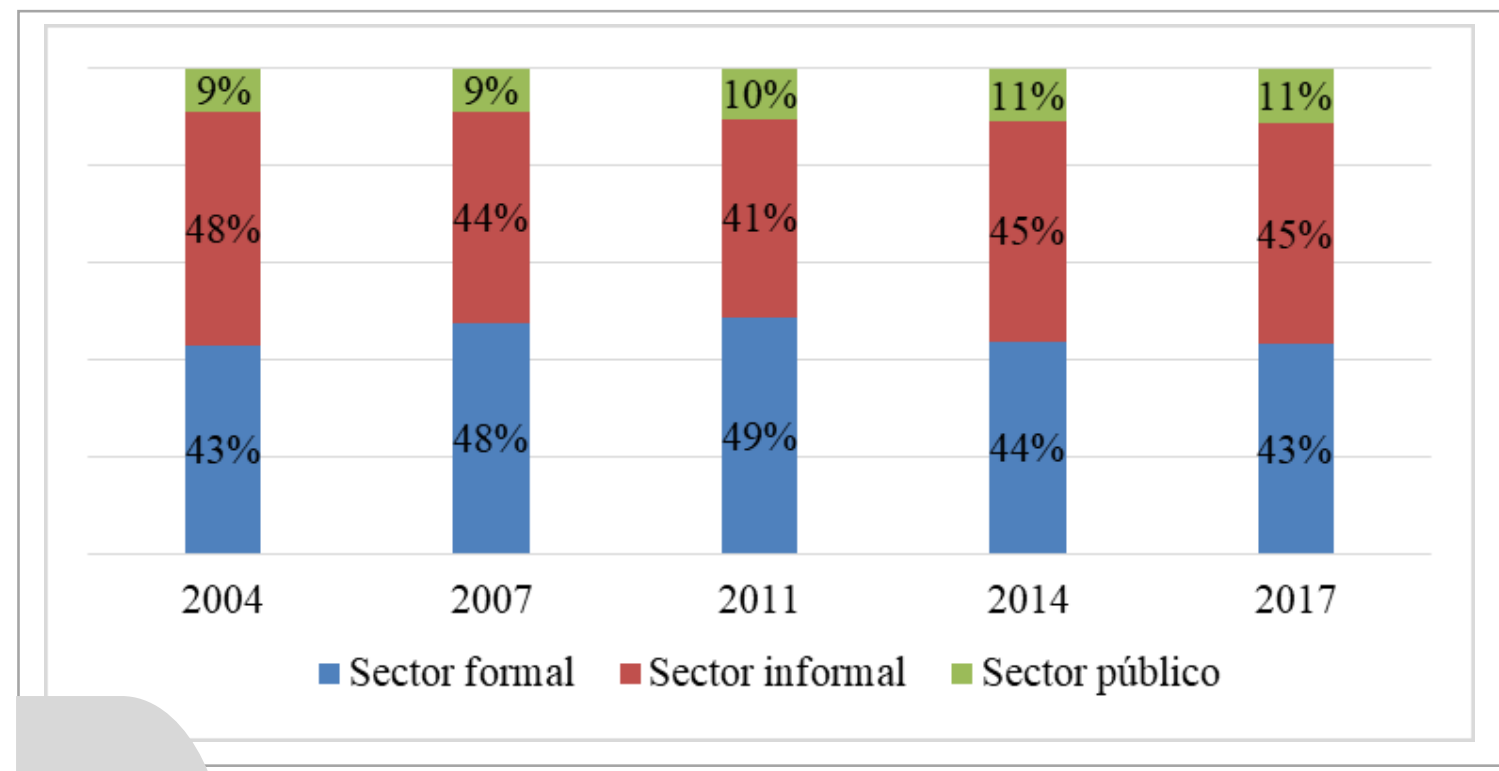

Gráfico 5 | Composición de la fuerza de trabajo ocupada joven, de 18 a 29 años, por sector de inserción. ${ }^{10}$ Total de aglomerados urbanos 2004-2017. Fuente: elaboración propia sobre la base de la información procesada por el Programa Cambio Estructural y Desigualdad Social del Instituto Gino Germani (FCS-UBA), a partir de la EPH, INDEC, cuartos trimestres, 2004, 2007, 2011, 2014 y 2017

Al respecto, según datos del último censo (INDEC, 2010), la preponderancia masculina se produce en la mayor parte de las ocupaciones, a excepción de las vinculadas a la salud y a la educación, donde las mujeres tienen una participación que asciende a $66 \%$ y a $73 \%$, respectivamente. Las mujeres predominan, también, en las actividades relacionadas con la limpieza doméstica y no doméstica, superando el $75 \%$.

La composición sectorial responde a lo desarrollado respecto de la participación de las mujeres en actividades directamente relacionadas con las tareas de cuidado, pero, además, a una presencia levemente superior en el sector menos dinámico de la estructura productiva, que nos lleva a indagar sobre la composición de los segmentos de empleo, es decir, sobre la calidad de los puestos de trabajo a los que accede la población joven en la Argentina. 


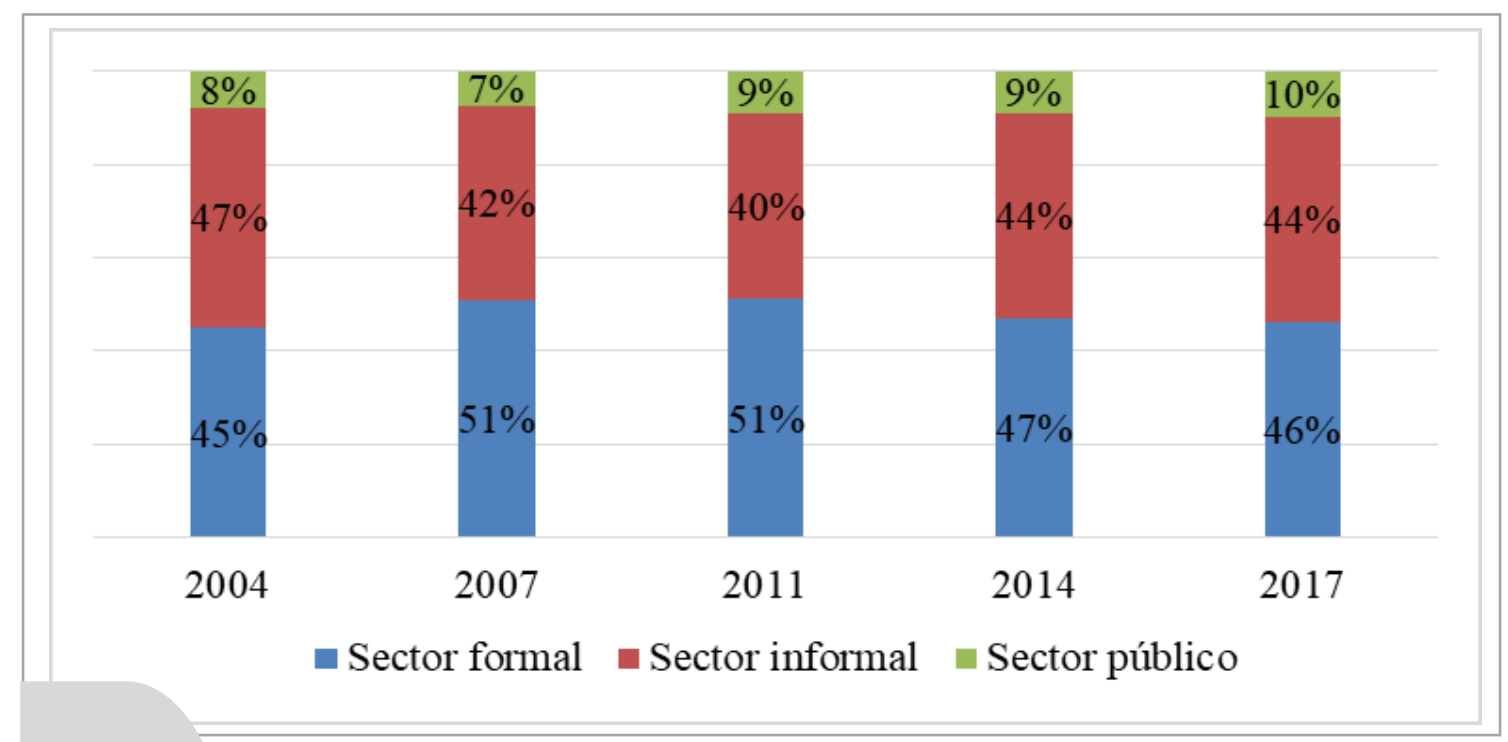

Gráfico 6 | Composición de la fuerza de trabajo masculina ocupada joven, de 18 a 29 años, por sector de inserción.

Total de aglomerados urbanos 2004-2017.

Fuente: elaboración propia sobre la base de la información procesada por el Programa Cambio Estructural y Desigualdad Social del Instituto Gino Germani (FCS-UBA), a partir de la EPH, INDEC, cuartos trimestres, 2004, 2007, 2011, 2014 y 2017

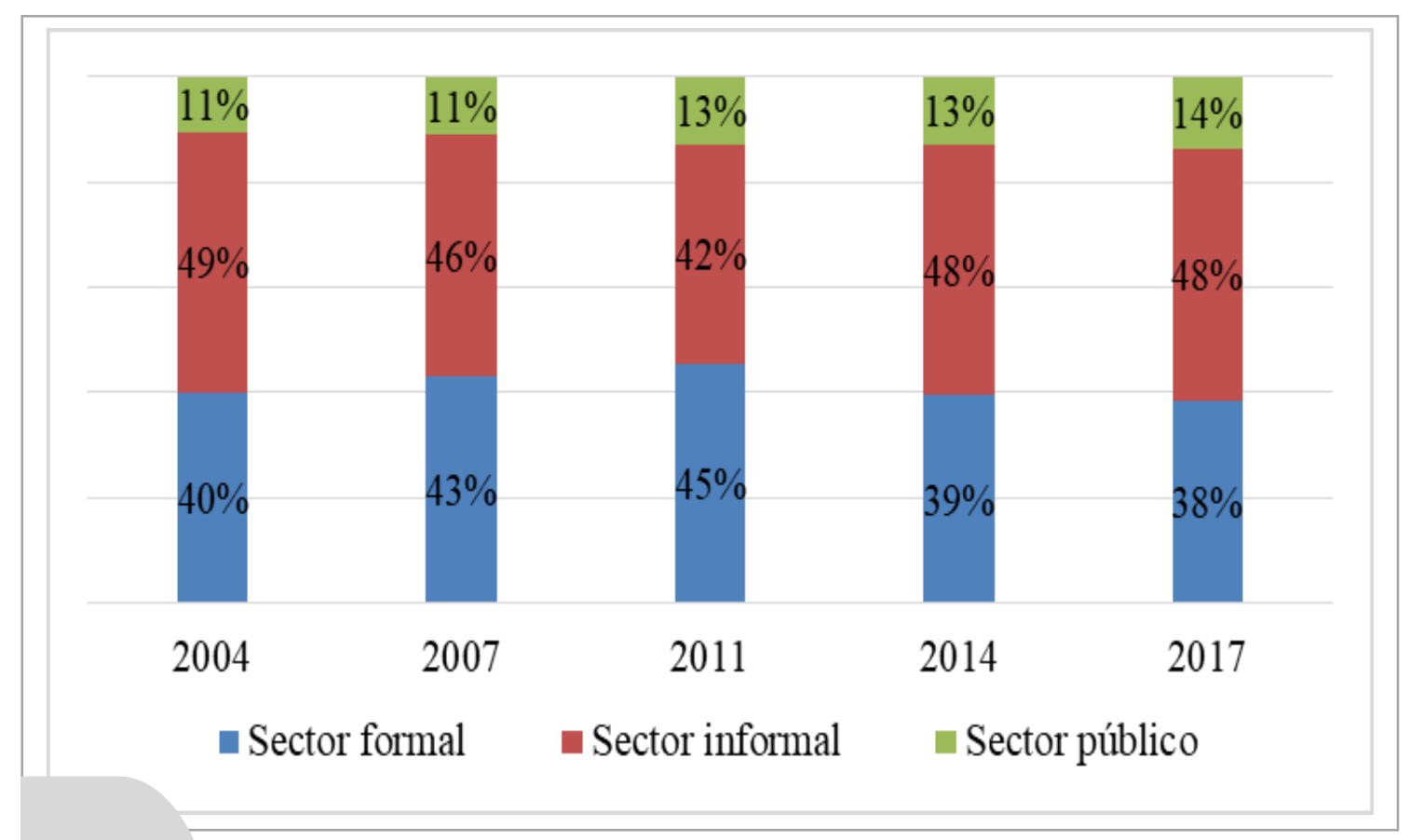

Gráfico 7 | Composición de la fuerza de trabajo femenina ocupada joven, de 18 a 29 años, por sector de inserción.

Total de aglomerados urbanos 2004-2017.

Fuente: elaboración propia sobre la base de la información procesada por el Programa Cambio Estructural y Desigualdad Social del Instituto Gino Germani (FCS-UBA), a partir de la EPH, INDEC, cuartos trimestres, 2004, 2007, 2011, 2014 y 2017 


\section{Según segmento de empleo}

A lo largo del período estudiado, la población joven se inserta mayoritariamente en el segmento no regulado del empleo, diferencia que se acentúa hacia las puntas del período. En 2004, el segmento regulado representa 28\%, valor que asciende hasta 45\% en 2011, para luego volver a descender hasta 37\% en 2017 [Gráfico 8].

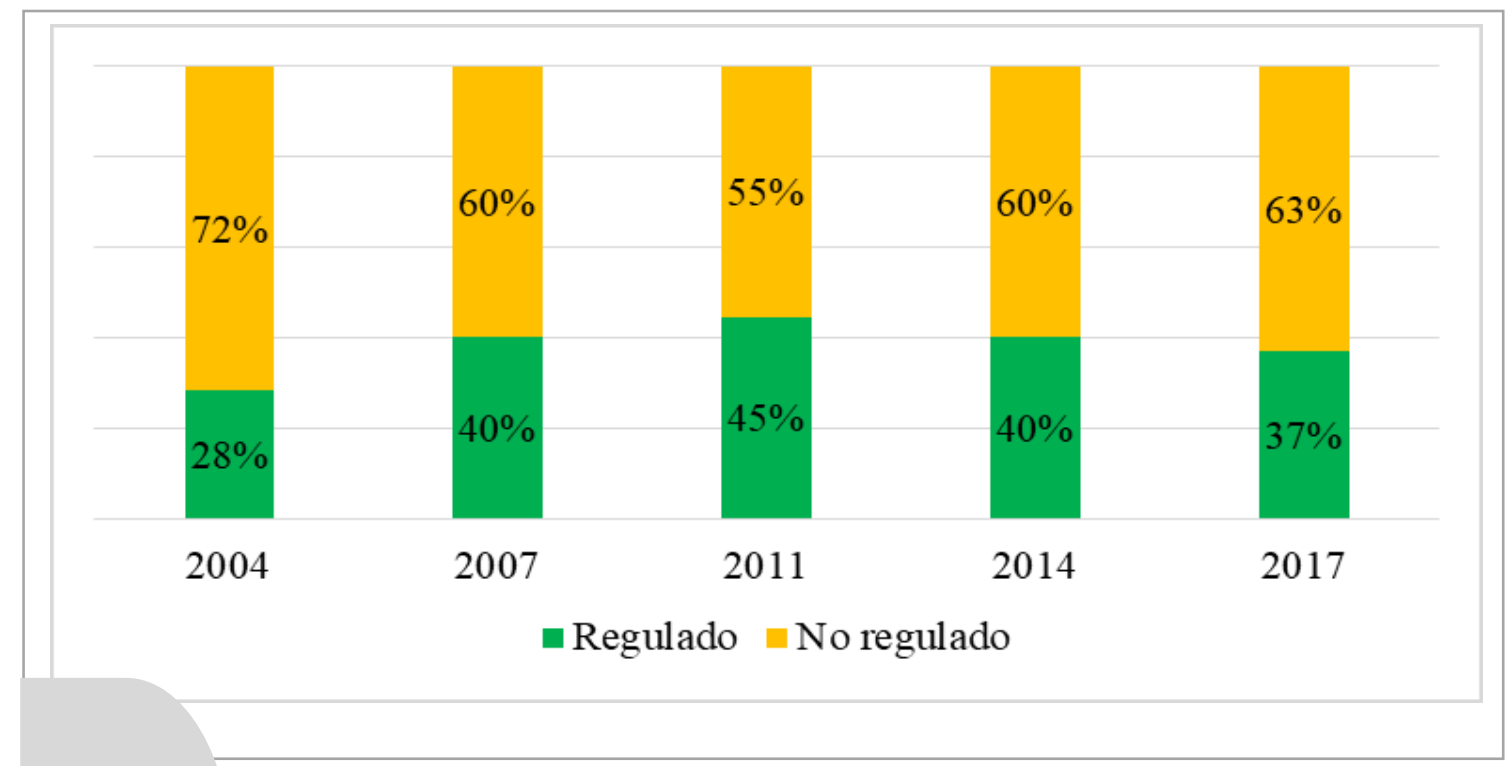

Gráfico 8 | Composición de la fuerza de trabajo ocupada joven, de 18 a 29 años, por segmento. Total de aglomerados urbanos 2004-2017.

Fuente: elaboración propia sobre la base de la información procesada por el Programa Cambio Estructural y Desigualdad Social del Instituto Gino Germani (FCS-UBA), a partir de la EPH, INDEC, cuartos trimestres, 2004, 2007, 2011, 2014 y 2017

Si bien para ambos sexos se observa una evolución similar en la composición de los segmentos, los varones poseen siempre mayor porcentaje de empleos regulados que las mujeres, con una diferencia que oscila entre 2\% y 5\% [Gráficos 9 y 10]. 


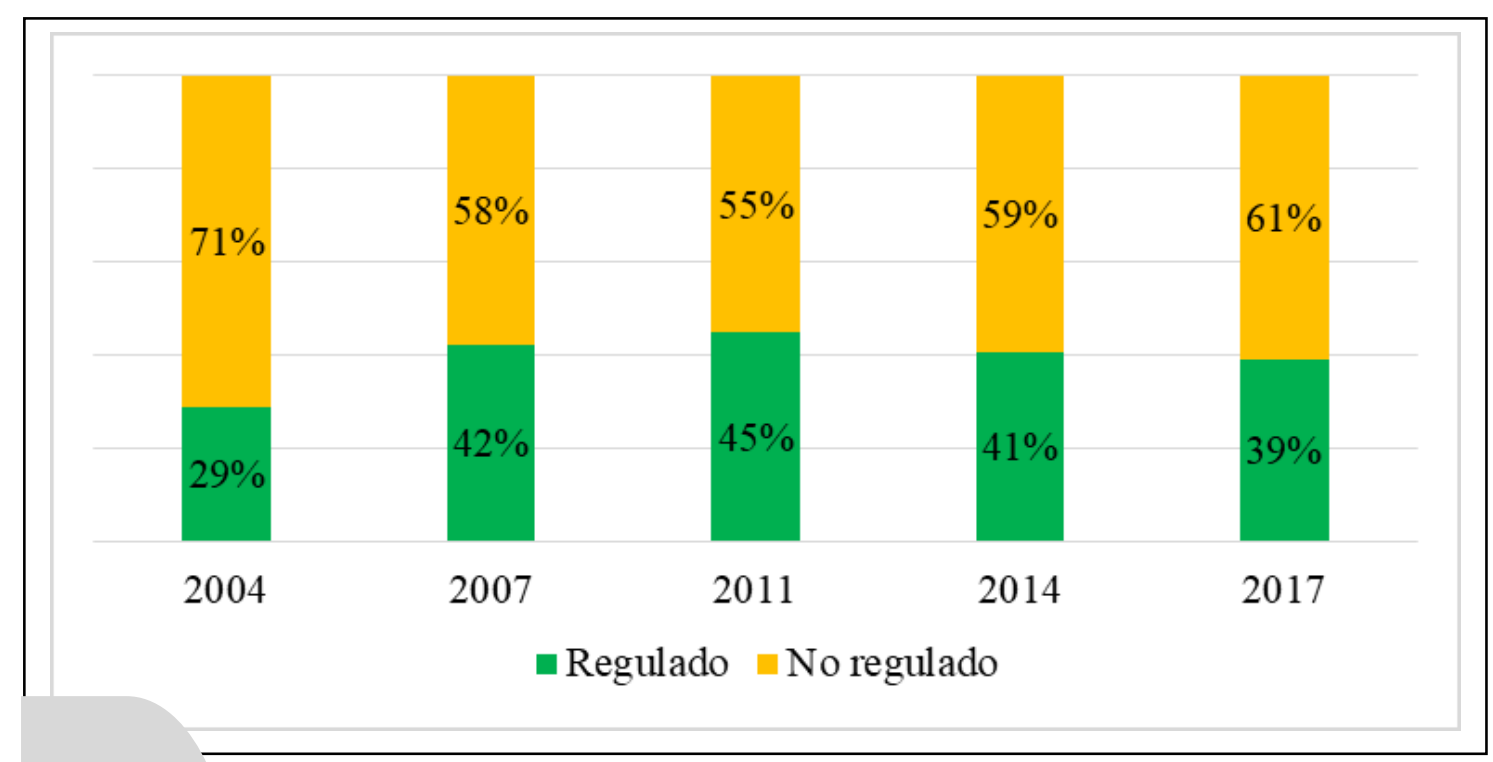

Gráfico 9 | Composición de la fuerza de trabajo masculina ocupada joven, de 18 a 29 años, por segmento.

Total de aglomerados urbanos 2004-2017.

Fuente: elaboración propia sobre la base de la información procesada por el Programa Cambio Estructural y Desigualdad Social del Instituto Gino Germani (FCS-UBA), a partir de la EPH, INDEC, cuartos trimestres, 2004, 2007, 2011, 2014 y 2017

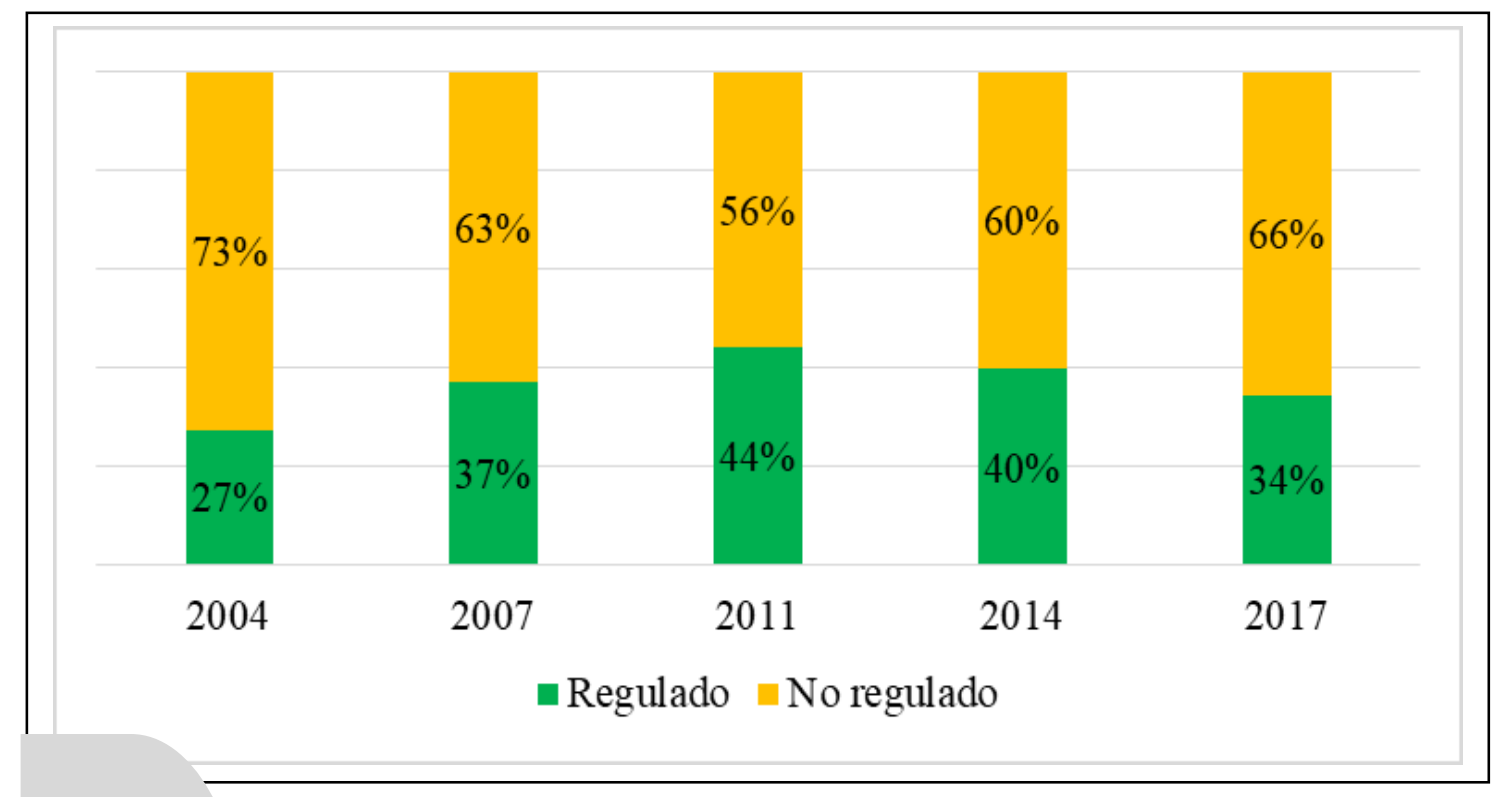

Gráfico 10 | Composición de la fuerza de trabajo femenina ocupada joven, de 18 a 29 años, por segmento.

Total de aglomerados urbanos 2004-2017.

Fuente: elaboración propia sobre la base de la información procesada por el Programa Cambio Estructural y Desigualdad Social del Instituto Gino Germani (FCS-UBA), a partir de la EPH, INDEC, cuartos trimestres, 2004, 2007, 2011, 2014 y 2017 
Habiendo caracterizado hasta aquí la participación de los/as jóvenes en el mercado laboral, nos interesa avanzar en un tipo de análisis predictivo y explicativo que permita profundizar en los factores que inciden en esta población a la hora de acceder a un empleo de calidad.

Presentamos, a continuación, modelos de regresión logística binaria. Este tipo de análisis multivariado permite analizar la relación de las variables independientes con una dependiente dicotómica. De esta forma, podremos saber cuál es el efecto de una variable independiente, una vez controlado el resto; por ejemplo, podremos saber cuál es el efecto neto de ser mujer sobre estar inserto en un empleo precario, controlado, a su vez, un conjunto de otras variables como grupos de edad, sector de inserción, nivel educativo, etcétera.

\section{Modelos de regresión logística binomial}

El propósito de los modelos consiste en predecir la probabilidad de que trabajadores/as jóvenes del total de aglomerados urbanos de la Argentina tengan un empleo en el segmento no regulado, en los años tomados en cuenta para el análisis, determinando los factores que más pesan para aumentar o para disminuir la posibilidad de que este evento ocurra. Los resultados estadísticos de este primer modelo se interpretan como «múltiples efectos principales» (Mood, 2010), e indican que tanto el sexo, como el nivel educativo, el sector, etcétera, están relacionados con la probabilidad de pertenecer al segmento no regulado de empleo.

Adicionalmente, realizamos regresiones logísticas para hombres y para mujeres que nos permiten ver si el resto de las variables independientes tienen efectos diferenciales según el sexo. Esto permite observar cómo las posiciones interseccionales pueden reflejar una moderación o una exacerbación de una desventaja según sexo (Krause \& Ballesteros, 2018). De esta forma, podemos acercarnos al estudio de la forma en la que los distintos determinantes en la inserción laboral de calidad para la población joven tienen efectos diferenciales según sexo. 
Cuando observamos el modelo para el total de jóvenes ocupados/as, se aprecia que el sector de inserción es la variable con mayor fuerza explicativa puesto que, habiendo controlado el resto de las variables, la probabilidad de que los/as jóvenes ocupados/as pertenezcan al segmento no regulado de empleo es 38,7 \% mayor entre los/as que se encuentran insertos en el sector micro informal, respecto a los/as que se encuentran trabajando en el sector formal, sea público o privado.

La siguiente variable, en términos de fuerza explicativa, es el nivel educativo: quienes no han completado el secundario tienen 15,8\% más de probabilidades de pertenecer al segmento no regulado que quienes completaron el nivel medio o más. Luego, vemos que los/as jóvenes de 18 a 24 años registran 11,5\% más de probabilidades de pertenecer al segmento precario respecto a los/as jóvenes adultos/as de 25 a 29 años, y que el año 2004, de reciente salida de la crisis, presenta mayores probabilidades de no regulación (11,9\%), seguido por el año 2017 (5,73\%) y luego por 2007 y 2014 con menores probabilidades, pero siempre superando respecto a 2011 que fue un año de bonanza en el periodo de la posconvertibilidad.

Las otras dos variables incorporadas al modelo, sexo y categoría ocupacional, poseen una fuerza explicativa menor pero igualmente significativa: las mujeres jóvenes presentan 4,5\% más de probabilidades de pertenecer al segmento no regulado respecto a sus pares hombres, y los/as no asalariados/as casi $4 \%$ más probabilidades respecto a los/as asalariados/as.

Podemos afirmar, pues, que si se mantienen constantes el resto de las variables, en primer lugar, el sector de inserción y, en segundo lugar, la educación son las variables que mayor peso tienen en la población joven para pertenecer al segmento no regulado de la estructura productiva, muy por encima de las demás condiciones, aunque estas no arrojen coeficientes despreciables para explicar ese fenómeno.

Si se realiza por separado la regresión para hombres y para mujeres [Cuadro 2] se observa, en primer lugar, que el subgrupo etario no presenta variaciones según sexo, manteniendo sus probabilidades respecto al fenómeno como en el conjunto del grupo. Sin embargo, las desigualdades educativas en la pertenencia al segmento no regulado aumentan entre las mujeres y disminuyen entre los hombres. 
Las probabilidades de las mujeres jóvenes que no han alcanzado a completar el nivel secundario de pertenecer al segmento no regulado son $16,4 \%$ mayores que las que han alcanzado ese nivel o algún nivel educativo mayor; mientras que en los hombres esas probabilidades son $15,4 \%$ mayores.

\begin{tabular}{|c|c|c|c|}
\hline Jóvenes ocupados 18 a 29 años & $\begin{array}{l}\text { Total } \\
\text { PEM }\end{array}$ & $\begin{array}{l}\text { Hombres } \\
\text { PEM }\end{array}$ & $\begin{array}{c}\text { Mujeres } \\
\text { PEM }\end{array}$ \\
\hline \multicolumn{4}{|l|}{ Sexo (Referencia: Varón) } \\
\hline Mujer & $4.5^{\star \star *}$ & & \\
\hline \multicolumn{4}{|l|}{ Subgrupo etario (Referencia: 25 a 29 años) } \\
\hline 18 a 24 años & $11.5^{\star \star \star}$ & $11.5^{\star \star \star}$ & $11.4^{\star \star \star}$ \\
\hline \multicolumn{4}{|l|}{ Nivel educativo (Referencia: SC o más) } \\
\hline HSI & $15.8^{\star \star \star}$ & $15.4^{\star \star \star}$ & $16.4^{\star * \star}$ \\
\hline \multicolumn{4}{|l|}{$\begin{array}{l}\text { Sector de inserción } \\
\text { (Referencia: Sector Formal Público y Privado) }\end{array}$} \\
\hline $\begin{array}{ll}\text { Sector Micro Informal } \\
\end{array}$ & $38.7^{\star \star \star}$ & $41.0^{\star \star \star}$ & $34.4^{\star \star \star}$ \\
\hline \multicolumn{4}{|l|}{ Categoría ocupacional (Referencia: Asalariados) } \\
\hline No Asalariados & $3.99 * \star \star$ & $-3.06^{*}$ & $13.7^{\star \star \star}$ \\
\hline \multicolumn{4}{|l|}{ Años } \\
\hline 2004 & $11.9^{\star \star \star}$ & $12.2^{\star \star \star}$ & $11.8^{\star \star \star}$ \\
\hline 2007 & $2.81^{\star \star}$ & 2.00 & $4.20^{\star \star}$ \\
\hline 2014 & $2.05^{*}$ & 2.37 & 1.46 \\
\hline 2017 & $5.73^{* * *}$ & $4.76^{\star \star \star}$ & $7.21^{\star \star \star}$ \\
\hline R cuadrado de McFadden & 0,214 & 0,211 & 0,223 \\
\hline $\mathrm{N}$ & 29,757 & 17,964 & 11,793 \\
\hline
\end{tabular}

Cuadro 2 | Tasas de actividad, de desocupación, de subempleo horario y de inactividad sobre la población joven (18 a 29 años) económicamente activa y ocupada, según sexo. Total de aglomerados urbanos 2004-2017.

Fuente: elaboración propia sobre la base de la información procesada por el Programa Cambio Estructural y Desigualdad Social del Instituto Gino Germani (FCS-UBA), a partir de la EPH, INDEC, cuartos trimestres, 2004, 2007, 2011, 2014 y 2017

Respecto a la categoría ocupacional, las mujeres presentan 13,7\% más probabilidades de pertenecer al segmento no regulado siendo no asalariadas, en tanto que los hombres registran 3,05\% menos probabilidades. Es decir, mientras que en el caso de las mujeres la condición de no asalariada penaliza, en los hombres premia, respecto a ser asalariado. Sobre esto, podríamos sospechar que por la edad cuando nos referimos a no asalariados no estamos refiriéndonos 
mayoritariamente a profesionales independientes, sino a trabajadores por cuenta propia, y si lo analizamos de forma segmentada podemos pensar en los altos porcentajes de empleadas en casas particulares para esta categoría ocupacional.

Respecto a los años, los hombres presentan mayores probabilidades de pertenencia al segmento no regulado en 2004 y las mujeres en 2007 y en 2017, siempre respecto a 2011, el mejor año del periodo. Por último, pertenecer al sector micro informal respecto al formal privado o público, aumenta las probabilidades de un empleo precario $41 \%$ para los hombres y $34 \%$ para las mujeres.

\section{Reflexiones finales}

La inserción de los/as jóvenes en el mercado laboral argentino es preocupante durante todo el período estudiado, ya que se observan altas tasas de inactividad (en aumento sostenido), de desempleo y de subocupación; a su vez, al interior de los/as jóvenes ocupados/as, la mayor parte pertenece al segmento no regulado. El aumento observado en los niveles educativos (puesto que cada vez hay más jóvenes que finalizan el nivel secundario) no pareciera venir acompañado ni de mayores ni de mejores oportunidades laborales.

En este panorama, las mujeres jóvenes se hallan en una situación de particular vulnerabilidad dado que tienen siempre menores tasas de actividad, de empleo y de asalarización, y mayores tasas de desocupación, de subocupación y de inactividad; además, la mitad de las inactivas jóvenes no asiste a un establecimiento educativo, lo que suele estar asociado a una mayor carga de tareas y de responsabilidades domésticas. Durante todo el período, la desigualdad de género se mantiene relativamente constante y resulta particularmente significativa si se tiene en cuenta que las mujeres jóvenes poseen niveles educativos mucho más altos que sus pares varones.

Al concentrarnos exclusivamente en los jóvenes ocupados, vemos que los porcentajes de inserción en el sector público y en el sector informal son mayores para las mujeres que para los varones, mientras que el porcentaje de inserción en el sector formal es mayor para los varones. Se observa, sin embargo, que en todos los años los porcentajes de pertenencia al segmento regulado son similares para 
ambos sexos. De este modo, se puede concluir que, si bien el sexo posee gran relevancia a la hora de estudiar la actividad, la subocupación o la desocupación de los/as jóvenes no dispone de mucho peso para explicar la calidad del empleo de los/as ocupados/as. En este punto, es mucho mayor el peso explicativo que poseen otras variables, como el sector de inserción, el nivel educativo, el subgrupo etario e, incluso, el año de relevamiento. Pero esto no significa, de cualquier manera, que el sexo sea completamente independiente del segmento de empleo, dado que, como se desprende de los modelos de regresión, al mantener constantes todas las otras variables consideradas las mujeres poseen mayores probabilidades de pertenecer al segmento no regulado.

En términos de interseccionalidad, los matices encontrados en la inserción ocupacional de los/as jóvenes muestran cómo el sexo, el sector de inserción, el subgrupo etario, la categoría ocupacional y el contexto sociohistórico coconstituyen las desigualdades sociales en el mundo laboral.

En este sentido, queda pendiente incorporar al análisis qué sucede con la calidad del empleo al interior de cada sector de inserción, ya que la distinción según sexo ha incorporado diferenciales de interés en los indicadores generales del mercado de trabajo, así como en la composición por sector y por nivel educativo, y la variable de segmento ha sido explicada, en gran medida, por la de sector en las regresiones presentadas. Sería relevante continuar indagando qué sucede al interior de los sectores de inserción, en donde las mujeres podrían estar participando mayoritariamente en puestos no regulados; precarios y peor remunerados, respecto a sus pares varones. Además, podrían presentarse interacciones con las distintas variables que podría impactar en la bondad de ajuste del modelo.

Al controlar cómo el sexo se combina con otros factores que estratifican a la población se obtuvieron resultados más finos que permiten concluir para este grupo mayores o menores grados de acceso a puestos de calidad. Estas desigualdades no se explican por el sexo, por el nivel educativo o por el sector de forma aislada, sino por su interacción. 


\begin{tabular}{|c|c|c|}
\hline SECTORES & $\begin{array}{l}\text { CATEGORÍA / } \\
\text { SECTOR }\end{array}$ & $\begin{array}{l}\text { OPERACIONALIZACIÓN Y } \\
\text { TIPO DE INGRESO DE CADA } \\
\text { CATEGORÍA/SECTOR }\end{array}$ \\
\hline \multirow{2}{*}{$\begin{array}{l}\text { SECTOR PRIVADO FORMAL } \\
\text { Actividades laborales de elevada } \\
\text { productividad y altamente integradas } \\
\text { económicamente a los procesos } \\
\text { de modernización. } \\
\text { Se las define habitualmente como aquellas } \\
\text { que conforman el mercado más } \\
\text { concentrado o estructurado. } \\
\text { En términos operativos, son ocupaciones } \\
\text { en establecimientos medianos o grandes o } \\
\text { actividades profesionales. }\end{array}$} & ASALARIADO & $\begin{array}{l}\text { Salarios como obrero } \\
\text { o empleado que trabaja } \\
\text { en establecimiento privado } \\
\text { con más de cinco ocupados. }\end{array}$ \\
\hline & $\begin{array}{c}\text { NO } \\
\text { ASALARIADO }\end{array}$ & $\begin{array}{l}\text { Utilidades como cuenta } \\
\text { propia profesional. Ganancias } \\
\text { como patrones profesionales } \\
\text { o de establecimientos } \\
\text { con más de cinco ocupados. }\end{array}$ \\
\hline \multirow{2}{*}{$\begin{array}{l}\text { SECTOR PRIVADO INFORMAL } \\
\text { Salarios como obrero o empleado no } \\
\text { profesional que trabaja en establecimiento } \\
\text { privado con hasta cinco ocupados. } \\
\text { Actividades laborales dominadas por la } \\
\text { baja productividad, alta rotación de } \\
\text { trabajadores, inestabilidad y su no } \\
\text { funcionalidad al mercado formal o más } \\
\text { estructurado. } \\
\text { En términos operativos, son ocupaciones } \\
\text { en establecimientos pequeños, actividades } \\
\text { de servicio doméstico o actividades } \\
\text { independientes no profesionales. }\end{array}$} & ASALARIADO & $\begin{array}{l}\text { Salarios como obrero } \\
\text { o empleado no profesional } \\
\text { que trabaja en establecimiento } \\
\text { privado con hasta cinco } \\
\text { ocupados. }\end{array}$ \\
\hline & $\begin{array}{c}\text { NO } \\
\text { ASALARIADO }\end{array}$ & $\begin{array}{l}\text { Utilidades como cuenta } \\
\text { propia o ayuda familiar } \\
\text { sin calificación profesional. } \\
\text { Ganancias como patrón } \\
\text { de establecimiento con hasta } \\
\text { cinco empleados con } \\
\text { calificación no profesional. } \\
\text { Ingresos como trabajador } \\
\text { que presta servicios domésticos } \\
\text { en hogares particulares. }{ }^{11}\end{array}$ \\
\hline $\begin{array}{l}\text { SECTOR PÚBLICO } \\
\text { Actividades laborales vinculadas al } \\
\text { desarrollo de la función estatal en sus } \\
\text { distintos niveles de gestión. Es decir, } \\
\text { ocupaciones en el sector público nacional, } \\
\text { provincial o municipal. }\end{array}$ & ASALARIADOS & $\begin{array}{l}\text { Salarios de obrero y empleado } \\
\text { ocupado en el sector público. } \\
\text { Salarios de beneficiarios de } \\
\text { programas sociales que } \\
\text { realizan contraprestación } \\
\text { laboral para el sector público. }\end{array}$ \\
\hline
\end{tabular}

Cuadro 3 | Desglose de los sectores y las categorías económico-ocupacionales de la ocupación principal y de los ingresos provenientes de la misma.

Fuente: Programa Cambio Estructural y Desigualdad Social, Instituto Gino Germani (FCS, UBA) sobre la base de datos de la EPH, INDEC 
Incluye a los asalariados con trabajo permanente e integrados a la Seguridad Social (con descuento jubilatorio) y a los trabajadores independientes (patrones y cuenta propia) que trabajan más de 34 horas o trabajan menos y no desean trabajar más horas y que no buscan otra ocupación.

SEGMENTO SECUNDARIO / EMPLEO PRECARIO / EMPLEO NO REGULADO

Incluye a los asalariados sin jubilación y a los trabajadores independientes (patrones o cuenta propia) que estaban subocupados (menos de 35 hs.) y deseaban trabajar más horas, o estaban subocupados y buscaban otra ocupación, o bien que trabajaban más de 35 hs. pero buscaban otra ocupación. También incluye a los no asalariados cuyo ingreso mensual estaba por debajo del ingreso del primer decil de los trabajadores asalariados no registrados.

Cuadro 4 | definiciones operacionales de la precariedad y los segmentos de empleo.

Fuente: Programa Cambio Estructural y Desigualdad Social, Instituto Gino Germani (FCS, UBA) sobre la base de datos de la EPH, INDEC

\section{Referencias}

Arelovich, S., Barrera, F., Belloni, P., Constantinto, A., Sabbatella, I.

y Wainer, A. (2017). La economía del primer año de Cambiemos.

Ciudad Autónoma de Buenos Aires, Argentina: Fundación Friedrich Ebert.

Recuperado de http://library.fes.de/pdf-

files/bueros/argentinien/13397.pdf

Bilge, S. (2010). Recent Feminist Outlooks on Intersectionality. Diogenes, 57(1), 58-72. Doi: https://doi.org/10.1177/0392192110374245

Krause, M. y Ballesteros, M. S. (2018). Interseccionalidad en desigualdades en salud en Argentina: discusiones teórico-metodológicas a partir de una encuesta poblacional. Hacia la promoción de la salud, 23(2), 13-33. Recuperado de http://190.15.17.25/promocionsalud/images/stories/iconopdf.jpg 
Banco Mundial (2005). Argentina, a la búsqueda de un crecimiento sostenido con equidad social. Observaciones sobre el crecimiento, la desigualdad y la pobreza. Documento 32553-AR. Recuperado de http://documentos.bancomundial.org/curated/es/125681468201588974/pd f/325530SPANISH01recimiento0Sostenido.pdf

Beccaria, L. y Groisman, F. (2015). Informalidad y segmentación del mercado laboral: el caso de la Argentina. Revista de la CEPAL, (117), 129-143. Recuperado de https://repositorio.cepal.org/bitstream/handle/11362/39471/REV117_Becca ria-Groisman.pdf?sequence $=1$

Beccaria, L., Maurizio, R. y Vázquez, G. (2015). Recent Decline in Wage Inequality and Formalization of the Labor Market in Argentina. International Review of Applied Economics, (29), 677-700.

Becker, G. S. (1962). Investment in Human Capital. A Theoretical Analysis. The Journal of Political Economy, 70(5), 9-49.

Busso, M. y Pérez, P. (Coords.) (2010). La corrosión del trabajo. Estudios sobre informalidad y precariedad laboral. Ciudad Autónoma de Buenos Aires, Argentina: Miño y Dávila / CEIL-PIETTE / Trabajo y Sociedad.

Cantamutto, F. y Schorr, M. (2016). El gobierno de Macri: ajuste regresivo, nuevo ciclo de endeudamiento externo y cuantiosas transferencias de ingresos al poder económico. En J. Marchini y E. Lucita (Eds.). Anuario EDl: ¿A dónde va la economía del gobierno de Macri? (pp. 12-14). Ciudad Autónoma de Buenos Aires, Argentina: Fundación Rosa Luxemburgo. 
Centro de Investigación y Formación de la República Argentina (CIFRA) (2016). La naturaleza política y económica de la Alianza Cambiemos.

Ciudad Autónoma de Buenos Aires, Argentina: Central de Trabajadores de la Argentina (CTA) / Facultad Latinoamericana de Ciencias Sociales (FLACSO). Recuperado de http://www.centrocifra.org.ar/publicacion.php?pid=92

Cerrutti, M. (2000). Determinantes de la participación intermitente de las mujeres en el mercado de trabajo del Área Metropolitana de Buenos Aires. Desarrollo Económico, 39(156), 619-638.

Cerruti, M. y Binstock, G. (2009). Familias latinoamericanas en transformación: desafíos y demandas para la acción pública. Serie Políticas sociales de la CEPAL, (147). Recuperado de https://repositorio.cepal.org/handle/11362/6153

Choo, H. y Ferree, M. (2010). Practicing Intersectionality in Sociological Research: A Critical Analisis of Inclusions, Interactions, and Institutions in the Study of Inequalities. Sociological theory, 28(2), 129-149.

Comisión Económica para América Latina y el Caribe (CEPAL) (2007). El aporte de las mujeres a la igualdad en América Latina y el Caribe. Recuperado de https://repositorio.cepal.org/bitstream/handle/11362/2855/1/S32820 07_es.pdf

Comisión Económica para América Latina y el Caribe (CEPAL) (2010). La hora de la igualdad: brechas por cerrar, caminos por abrir. Recuperado de https://repositorio.cepal.org/bitstream/handle/11362/13309/S201098 6_es.pdf 
Comisión Económica para América Latina y el Caribe (CEPAL) (2014).

Panorama Social de América Latina. Recuperado de

https://www.cepal.org/es/publicaciones/37626-panorama-social-americalatina-2014

Comisión Económica para América Latina y el Caribe (CEPAL) (2015).

Juventud: realidades y retos para un desarrollo con igualdad.

Recuperado de

http://repositorio.cepal.org/bitstream/handle/11362/38978/S1500718_es.p

$\mathrm{df}$ ?sequence $=4$

Comisión Económica para América Latina y el Caribe (CEPAL)

y Organización Iberoamericana de Juventud (OIJ) (2004). La juventud

en Iberoamérica: tendencias y urgencias. Santiago de Chile, Chile:

Naciones Unidas. Recuperado de

http://repositorio.cepal.org/bitstream/handle/11362/2785/S2004083_es.p

df;jsessionid=27037B77183754F79D6185007EB23B72? sequence=1

De Oliveira, O. (2006). Jóvenes y precariedad laboral en México.

Papeles de población, (49), 37-73. Recuperado de:

http://www.redalyc.org/articulo.oa?id=11204902

De Oliveira, O. y Ariza, M. (1997). División sexual del trabajo y exclusión social. Revista Latinoamericana de Estudios del Trabajo, 3(5), 183-202.

Else-Quest, N. M. y Hyde, J. S. (2016). Intersectionality in quantitative psychological research: II. Methods and techniques. Psychology of Women Quarterly, 40(3), 319-336. Doi:

https://doi.org/10.1177\%2F0361684316647953

Espino, A. (2011). Trabajo y género: un viejo tema, ¿nuevas miradas? Nueva Sociedad, (232), 87-102. Recuperado de https://nuso.org/articulo/trabajo-y-genero-un-viejo-tema-nuevasmiradas/ 
Esquivel, V. (2007). "Género y diferenciales de salarios en la Argentina». En M. Novick y H. Palomino H. (Coords.), Estructura productiva y empleo. Un enfoque transversal, (pp. 363-393). Ciudad Autónoma de Buenos Aires, Argentina: Ministerio de Trabajo, Empleo y Seguridad Social.

Feliz, M., López, E. y Álvarez Hayes, S. (agosto de 2009). Los patrones distributivos y su articulación con la acumulación de capital en una economía periférica (Argentina, 1995-2007). Un estudio a partir de la Encuesta a Grandes Empresas. En A. Marshall (Coord.), Actas del $9^{\circ}$ Congreso Nacional de Estudios del Trabajo de la Asociación Argentina de Especialistas en Estudios del Trabajo (ASET). Recuperado de https://www.aset.org.ar/congresos/9/Ponencias/p2_Feliz.pdf

Fernández Massi, M. (2014). Una mirada sectorial sobre las inserciones laborales precarias de los jóvenes en Argentina. En P. Pérez y M. Busso (Coords.), Tiempos contingentes: inserción laboral de los jóvenes en la Argentina posneoliberal. Ciudad Autónoma de Buenos Aires, Argentina: Miño y Dávila / CEIL-PIETTE / Trabajo y Sociedad.

Flores, R., Brenta, N., De Miguel, M., Partenio, F. y Schorr, M. (2018). La economía Argentina a dos años del gobierno de Cambiemos. Ciudad Autónoma de Buenos Aires, Argentina: Fundación Friedrich Ebert. Recuperado de http://library.fes.de/pdf-files/bueros/argentinien/14511.pdf

Freytes, C. y Niedzwiecki, S. (2018). Argentina 2017: la dinámica intertemporal de la reestructuración económica. Revista de Ciencia Política, 38(2), 125-158. Recuperado de https://scielo.conicyt.cl/pdf/revcipol/v38n2/0718-090X-revcipol-3802-0125.pdf

Gallart, M. A. (2008). Competencias, productividad y crecimiento del empleo. El caso de América Latina. Montevideo, Uruguay: Oficina Internacional del Trabajo (OIT), Cinterfor. Recuperado de https://www.oitcinterfor.org/sites/default/files/file_publicacion/gallart. pdf 
Gasparini, L., Galiani, S., Cruces, G. y Acosta, P. (2011). Educational Upgrading and Returns to Skills in Latin America: Evidence from a SupplyDemand Framework, 1990-2010. IZA Discussion Paper, (6244).

Recuperado de http://www.cedlas.econo.unlp.edu.ar/wp/wpcontent/uploads/IZA-WAGE-PREMIUM.pdf

Grimshaw, D., Fagan, C., Hebson, G. y Tavara, I. (2017). Making Work More Equal. Manchester, United Kingdom: Manchester University Press.

Halperín Weisburd, L., Labiaguerre, J., De Sena, A., Gonzáles, M., Horen, B., Müller, G., Villadeamigo, J., Charvay, C., Halperín, C., Labiaguerre, E., Quiroga, L., Pujol Buch, V. y Chahbenderian, F. (2009). Cuestiones de género, mercado laboral y políticas sociales en América Latina. El caso argentino. Ciudad Autónoma de Buenos Aires, Argentina: Cuadernos del CEPED.

Halperín Weisburd, L., Labiaguerre, J., De Sena, A., Gonzáles, M., Horen, B., Müller, G., Villadeamigo, J., Charvay, C., Halperín, C., Labiaguerre, E., Quiroga, L., Pujol Buch, V. y Chahbenderian, F. (2011). Problemas de género en la Argentina del siglo XXI: feminización de la pobreza e inequidad del mercado laboral. Ciudad Autónoma de Buenos Aires, Argentina: Cuadernos del CEPED.

Instituto Nacional de Estadísticas y Censo (INDEC) (2010). Censo Nacional de Población, Hogares y Viviendas 2010. Recuperado de https://www.indec.gob.ar/indec/web/Nivel4-Tema-2-41-135

Jacinto, C. (2004). «Ante la polarización de oportunidades laborales de los jóvenes en América Latina. Un análisis de algunas propuestas recientes en la formación para el trabajo». En C. Jacinto (Coord.), ¿Educar para qué trabajo? Discutiendo rumbos en América Latina (pp. 187-200). Ciudad Autónoma de Buenos Aires, Argentina: La Crujía. 
La Barbera, M. C. (2016). Interseccionalidad, un «concepto viajero»: orígenes, desarrollo e implementación en la Unión Europea.

Interdisciplina, 4(8), 105-122.

Doi: http://dx.doi.org/10.22201/ceiich.24485705e.2016.8.54971

Millenaar, V. y Jacinto, C. (2015). «Desigualdad social y género en las trayectorias laborales de jóvenes de sectores populares. El lugar de los dispositivos de inserción». En L. Mayer, D. Llanos y R. Unda Lara (Comps.), Socialización escolar: experiencias, procesos y trayectos (pp.73-100). Quito, Ecuador: Abya Ayala / Universidad Politécnica Salesiana.

Miranda, A., Otero, A. y Zelarayan, J. (agosto de 2005). Distribución de la educación y desigualdad en el empleo: los jóvenes en la Argentina contemporánea. Trabajo presentado en el $7^{\circ}$ Congreso Nacional de Estudios del Trabajo de la Asociación Argentina de Especialistas en Estudios del Trabajo (ASET). Recuperado de http://www.aset.org.ar/congresos/7/06002.pdf

Mood, C. (2010). Logistic Regression: Why We Cannot do What We Think We Can Do, and What We Can Do About It. European Sociological Review, 26(1), 67-82.

MTEySS e INDEC (2014). Indicadores más relevantes de la inserción de mujeres y los varones en el mercado de trabajo. Recuperado de http://www.trabajo.gov.ar/downloads/cegiot/140703_brochure.pdf

Muñíz Terra, L., Pla, J. y López Castro, N. (2016). «Estudios sobre la estructura social y el mundo del trabajo en los últimos años (2003-2014)». En S. Álvarez Leguizamón, A. J. Arias y L. Muñíz Terra (Coords.), Estudios sobre la estructura social en la Argentina contemporánea (pp. 59-142). Ciudad Autónoma de Buenos Aires, Argentina: Consejo Latinoamericano de Ciencias Sociales (CLACSO). Recuperado de http://www.memoria.fahce.unlp.edu.ar/libros/pm.618/pm.618.pdf 
Novick, M., Rojo, S. y Castillo, V. (Comps.) (2008). El trabajo femenino en la post convertibilidad. Argentina 2003-2007. Santiago de Chile, Chile: Comisión Económica para América Latina y el Caribe (CEPAL). Recuperado de https://bit.ly/2xTWK3L

Ocampo, J. A. (2001). Raúl Prebisch y la agenda del desarrollo en los albores del siglo XXI. Revista de la CEPAL, (75), 25-40. Recuperado de https://repositorio.cepal.org/handle/11362/10771

Organización Internacional del Trabajo (OIT) (2016a). Las mujeres en el trabajo. Recuperado de https://www.ilo.org/wcmsp5/groups/public/---dgreports/---dcomm/--publ/documents/publication/wcms_483214.pdf

Organización Internacional del Trabajo (OIT) (2016b). Young and Female A Double Strike? Gender Analysis of School-to-work Transition Surveys in 32 Developing Countries. Recuperado de https://www.ilo.org/wcmsp5/groups/public/--ed_emp/documents/publication/wcms_447495.pdf

Pérez, P. (2008). La inserción ocupacional de los jóvenes en un contexto de desempleo masivo. El caso argentino entre 1995 y 2003. Ciudad Autónoma de Buenos Aires, Argentina: Miño y Dávila / Ceil-Piette CONICET.

Pérez, P., Deleo, C. y Fernández Massi, M. (2013). Desigualdades sociales en trayectorias laborales de jóvenes en la Argentina. Revista Latinoamericana de Población, 7(13), 61-89. Recuperado de http://www.redalyc.org/pdf/3238/323830085003.pdf

Pérez, P. y Busso, M. (2018). «uventudes, educación y trabajo». En J. I. Pioviani y A. Salvia (Coords.), La Argentina en el Siglo XXI. Cómo somos, vivimos y convivimos en una sociedad desigual (pp. 569-592). Ciudad Autónoma de Buenos Aires, Argentina: Siglo XXI. 
Perry, G., Maloney, W., Arias, O., Fajnzylber, P., Mason, A. y SaavedraChanduvi, J. (2007). Informality: Exit and Exclusion. Latin American and Caribbean Studies. Washington, United States: World Bank. Recuperado de http://hdl.handle.net/10986/6730

Pinto, A. (1970). «Naturaleza e implicaciones de la "heterogeneidad estructural” de la América Latina». En AA.W, Dos polémicas sobre el desarrollo de América Latina (pp. 173-194). Santiago de Chile, Chile: Editorial universitaria. Recuperado de https://repositorio.cepal.org/bitstream/handle/11362/1914/S33098159D _es.pdf?sequence $=1 \&$ isAllowed $=y$

Pinto, A. (1976). La CEPAL y el problema del progreso técnico. El Trimestre Económico, 43(170), 267-284.

Piore, M. (1975). «Notes for a Theory of Labor Market Stratification». En D. Gordon, R. Edwards y M. Reich (Eds.), Labor Market Segmentation (pp. 125-149). Lexington, United States: Mass.

Programa de Naciones Unidas para el Desarrollo (PNUD) (2011). Género en cifras: mujeres y varones en la sociedad argentina. Recuperado de http://www.ar.undp.org/content/dam/argentina/Publications/G\%C3\%A9n ero/G\%C3\%A9nero\%20en\%20cifras_23.06.pdf

Programa de Naciones Unidas para el Desarrollo (PNUD) (2014). Género en el trabajo: brechas en el acceso a puestos de decisión. Recuperado de http://www.ar.undp.org/content/dam/argentina/Publications/Desarrollo\% 20Humano/PNUD\%20ARGENTINA\%20_Aportes_8.pdf

Prebisch, R. (1949). El desarrollo económico de la América Latina y algunos de sus principales problemas. Santiago de Chile, Chile: Comisión Económica para América Latina y el Caribe (CEPAL). 
Rodríguez, O. (2001). Prebisch: actualidad de sus ideas básicas.

Revista de La CEPAL, (75), 41-52. Recuperado de

https://repositorio.cepal.org/handle/11362/10772

Rojo Brizuela, S. y Tumini, L. (2009). Inequidades de género en el mercado de trabajo de la Argentina: las brechas salariales. Revista de trabajo, Nueva Época, 4(6), 53-71.

Rubio, B. y Fachal, M. N. (2018). Principales tendencias en el vínculo educación y empleo: los jóvenes en la Argentina de la postconvertibilidad (2004-2014). Entre Diversidades, (10), 59-98. Recuperado de http://entrediversidades.unach.mx/index.php/entrediversidades/article/vi $\mathrm{ew} / 3 / 8$

Rubio, B. y Salvia, A. (2018). Los jóvenes en el mercado laboral argentino bajo regímenes macroeconómicos diferentes: neoliberalismo y neodesarrollismo (1992-2014). Revista Colombiana de Ciencias Sociales, (9), 177-209. Doi: http://dx.doi.org/10.21501/22161201.2343

Salvia, A. y Vera, J. (2011). «Las desigualdades estructurales y el efecto de la educación sobre las oportunidades de empleo pleno». En J. Lindenboim y A. Salvia (Comps.), Hora de Balance. Proceso de acumulación, mercado de trabajo y bienestar. Argentina, 2002-2014 (pp. 211-246). Ciudad Autónoma de Buenos Aires, Argentina: Eudeba. Recuperado de https://www.aacademica.org/agustin.salvia/339

Salvia, A., Vera, J. y Poy, S. (2015). «Cambios y continuidades en la estructura ocupacional urbana argentina». En J. Lindenboim y A. Salvia (Comps.), Hora de balance: proceso de acumulación, mercado de trabajo y bienestar. Argentina, 2002-2014 (pp. 133-172). Ciudad Autónoma de Buenos Aires, Argentina: Eudeba. Recuperado de https://www.aacademica.org/agustin.salvia/285 
Salvia, A. y Tuñón, I. (2007). «Diferenciales de género en el Ingreso Horario en el Gran Buenos Aires: una desigualdad que perdura a compás de la feminización de la oferta laboral». En A. Salvia, A. Eguía y J. Piovani (Comps.), Género y trabajo. Estudios de las asimetrías intergéneros e intragéneros en áreas metropolitanas de la Argentina. 1992-2002 (pp. 25-50). Ciudad Autónoma de Buenos Aires, Argentina: EDUNTREF.

Schultz, T. W. (1961). Investment in Human Capital. The American Economic Review, 51(1), 1-17.

Terrones, M. y Calderón, C. (1993). Educación, capital humano y crecimiento económico: el caso de América Latina. Economía, (31), 23-70. Recuperado de http://revistas.pucp.edu.pe/index.php/economia/article/view/449

Tokman, V. (2004). Una voz en el camino. Empleo, Equidad en América Latina: 40 años de búsqueda. Santiago de Chile, Chile: Fondo de Cultura Económica.

UNICEF (2008). Acerca de la obligatoriedad en la escuela secundaria argentina. Análisis de la política nacional. Recuperado de https://www.unicef.org/argentina/spanish/doc_final_30_08.pdf

Vommaro, G., y Gené, M. (2017). Argentina: el año de Cambiemos. Revista de Ciencia Política, 37(2), 231-253. Recuperado de http://www.redalyc.org/pdf/324/32453264002.pdf

Weller, J. (2003). La problemática inserción laboral de los y las jóvenes. Santiago de Chile, Chile: Comisión Económica para América Latina y el Caribe (CEPAL). Recuperado de https://repositorio.cepal.org/handle/11362/5391 


\section{Notas}

1 Véase Cuadro 3 en el Anexo.

2 Véase Cuadro 4 en el Anexo.

3 Proporción de la población económicamente activa (PEA) respecto al total de la población.

4 Proporción de ocupados/as respecto a la PEA.

5 Proporción de desocupados/as respecto a la PEA.

6 Proporción de subocupados/as demandantes respecto a la PEA.

7 Proporción de asalariados/as respecto al total de ocupados/as.

8 Proporción de inactivos/as respecto al total de la población.

9 Porcentaje de inactivos/as que asisten a un establecimiento educativo.

10 El sector público excluye empleados/as ocupados/as en programas públicos de empleo.

11 Respecto a la categoría ocupacional «presta servicios domésticos en hogares particulares", en el presente trabajo hemos distinguido entre asalariados/as y no asalariados/as de acuerdo a la cantidad de horas semanales trabajadas y a la cantidad de hogares para los que trabaja. 